\section{Global Proceedings Repository \\ American Research Foundation}

ISSN 2476-017X

Available online at http://proceedings.sriweb.org

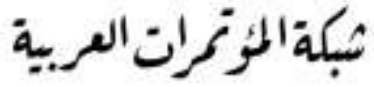

http://arab.kmshare.net/

ARF

The Ninth International Scientific Academic Conference

Under the Title "Contemporary trends in social, human, and natural sciences"

$$
\begin{aligned}
& \text { المؤتمر العلمي الاكاديمي الدولي التاسع } \\
& \text { تحت عنوان "الاتحاهات المعاصرة في العلوم الاجتماعية، الانسانية، والطبيعية" } \\
& 17 \text { - } 18 \text { يوليو -تموز } 2018 \text { - اسطنبول - تركيا }
\end{aligned}
$$

http://kmshare.net/isac2018/

\title{
قياس أثر التطورات في أسعار النفط على النمو الاقتصادي في دولة الكويت للمدة (2015-1990): دراسة تطبيقية
}

Measuring the impact of developments in oil prices on economic growth in the State of Kuwait for the period (19902015): An Empirical Study

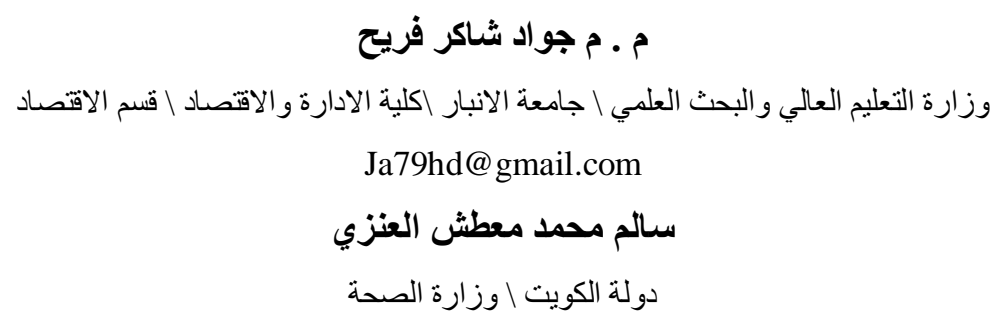

تهدف هذه الدراسة الى قياس اثر النطورات في أسعار النفط الخام على النمو الاقتصادي في دولة الكويت للفترة 1990-2015 باستخدام طريقة التكامل المشترك وتصحيح الخطأ، فقد تم تسخير معدل سعر برميل أوبك باعتبار ان دولة الكويت احد أعضاء هذه المنظمة كمتغير 


\section{Global Proceedings Repository \\ American Research Foundation}

ISSN 2476-017X

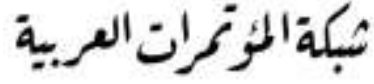

http://arab.kmshare.net/

ARF

Available online at http://proceedings. sriweb.org

$$
\begin{aligned}
& \text { تفسيري كما تم التعبير عن النمو الاقتصادي بمؤثرين ( الناتج المحلي الإجمالي بالأسعار الاسمية، الناتج المحلي الإجمالي بالأسعار } \\
& \text { الثابتة) كمتغيرات مفسره، نوصلت الدراسة الى أن أسعار النفط الخام تؤثر على النمو الاقتصادي بشكل طردي حيث أن كلما ارتفعت أسعار } \\
& \text { النفط أدى ذلك الى ارتفاع معدلات النمو الاقتصادي في دولة الكويت اذ بينت النتائج ان جميع الدوال جاءت معنوية عدا دالة معدل دخل } \\
& \text { الفرد بالأسعار الثابتة، كما بينت النتائج بوجود نوازن طويل الأمد بين مؤثرات النمو الاقتصادي وأسعار النفط الخام الا ان جميع هذه الدوال } \\
& \text { كانت غير مستقرة مما يعني عدم إمكانية التتبؤ بمؤشرات النمو بالاعتماد على أسعار النفط الخام خلال المدة 1990-2015 وأخيرا توصلت } \\
& \text { الدراسة الى وجود علاقة نوازنية قصيرة الاجل بين مؤشرات النمو الاقتصادي وأسعار النفط . }
\end{aligned}
$$

\begin{abstract}
:Abstract
This study aims to Measuring the effect of the impact of developments on the economic growth in the country of Kuwait for the period 1990-2015 using the co-integration style and error correction, it has been harnessing the price rate of a barrel of OPEC considering that the country of Kuwait is one of the members of this organization as a variable expository and it has been expressed of the economic growth

in Tow indicators, (gross domestic product (GDP) at nominal prices, GDP at constant prices) as
\end{abstract} explained variables, the study found that crude oil prices affect the economic growth in direct proportional; as crude oil prices have risen, this has led to high rates of economic growth in the country of Kuwait as the results showed that all functions were significant except the function of the individual income rate at constant prices, as results showed also the existence of a long-term balance between economic growth indicators and crude oil prices but all of these functions were unstable which means the unpredictability of growth indicators based on crude oil prices during the period 1990-2015. Finally, the study found the presence of a relationship of short-term equilibrium between economic growth and crude oil price

Keywords : the economic growth - oil prices 


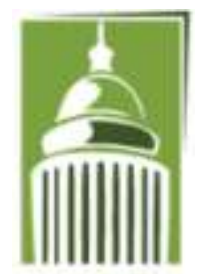

ARF
Global Proceedings Repository

American Research Foundation

ISSN 2476-017X
شبكةالمؤتمرات العربية

http://arab.kmshare.net/

Available online at http://proceedings.sriweb.org

البند الاول : الاطار النظري للبحث

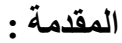

يعد النفط الخام أحد أهم مصادر الطاقة في العالم، ويشكل سلعة استر اتيجية دولية تتضمن قيمة اقتصادية عالية. وتأتى أهمية النفط الخام من

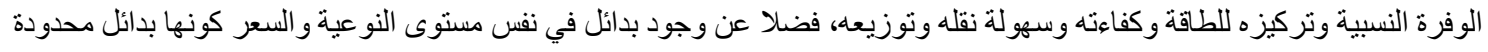
وبعضها يعد أكثر المصادر تلوثا للبيئة في حين يلاقي الأخر معارضة كبيرة بسبب الكلفة العالية وخطر الإثعاعات المنبعثة منها. وتخضع السوق العالمية للنفط إلى مجموعة من التطور ات المهمة قادت إلى حدوث اختلاف كبير في ميزان العرض والطلب، حيث أن السوق النفطية

ذو طبيعة خاصة تأخذ خصوصية من تداخل العوامل الاقتصادية مع العوامل السياسية، والتي تتفاوت أهميتها ودرجة تأثير ها على أسعار النفط الخام في السوق. وتعرضت أسعار النفط للعديد من التغيرات و عدم الاستقرار في الأسعار حيث كانت تعرف بالصدمات النفطية وكانت أول هذه الصدمات في

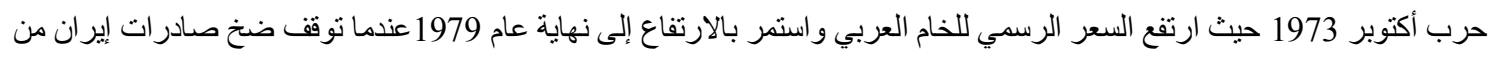
النفط ثم اندلاع الحرب العر اقية الإير انية في عام 1980 وارتفع منوسط سعر البرميل من النفطو هذا ما عرف بالصدمة النفطية الثانية، وفي الني

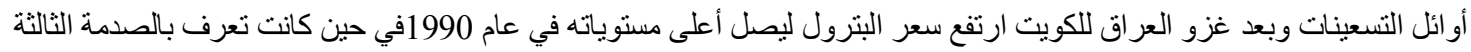

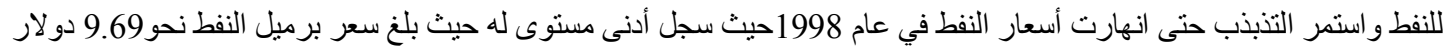
(سلسلة خامات أوبك) وذللك نتيجة الصر اع في حصص السوق للبلدان المنتجة وانخفاض الطلب العالمي على النفط وبعدها ارتفعت أسعار النفط و استمرت بالارتفاع حيث تجاوز برميل النفط 147 دولار للبرميل في عام 2008 ولكن بفعل الأزمة المالية في العالم انخفض الطلب على النفط. في حين إن تقلبات أسعار النفط لها عو اقب كبيرة على النشاط الاقتصادي فتراجع أسعار النفط يحمل اثأر ايجابية وسلبية في نفس الوقت تتمثل الآثار الايجابية انه خبر سار للاول المستوردة حيث تقوم باستير اد النفط بتكلفة اقل وبالتالي تتخفض التكاليف لقطاع الإعمال

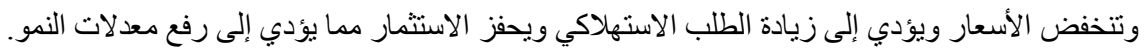

مشكلة الدراسة:

إن التغير ات التي تثهدها الأسواق النفطية ذات تأثنير كبير على الناتج المحلي الإجمالي الحقيقي في دولة الكويت إذ أنها من الدول التي تعتمد بشكل رئيسي على تصدير مادة النفط ولذلك فأن إي تغير بالأسعار سينعكس إيجابا أو سلباً على اقتصادها، ولذلك أن السؤ ال الرئيسي للارساسة

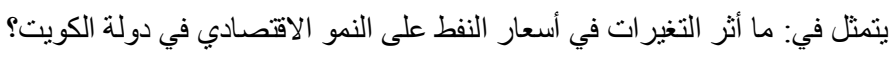
فرضيات الاراسة:

بناءً على مشكلة الدر اسة وبهدف تحقيق أهداف الدراسة تنطلق الفرضية الرئيسية من وجود اثر إيجابي لأسعار النفط الخام على مؤشر ات النمو الاقتصادي، اذ يمكن ان تتفرع الى فرضيتين رئيسيتين: يؤثر الارتفاع في أسعار النفط بشكل طردي على النق الناتج المحلي الإجمالي الاسمي

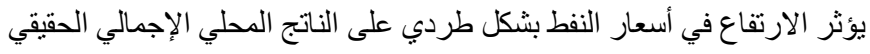

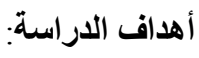




\section{Global Proceedings Repository American Research Foundation}

ISSN 2476-017X

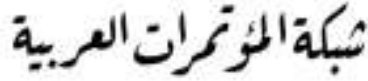

http://arab.kmshare.net/

Available online at http://proceedings.sriweb.org

تهدف الدر اسة إلى تحقيق الأهداف الآتية:

التعرف على التغير ات في أسعار النفط الخام خلال المدة 1990-2015.

تحديد ما إذا كان النمو في الناتج المحلي الإجمالي يتحدد على أساس النطورات في أسعار النفط. أهمية الاراسة: تظهر أهمية الدراسة من خلال تحليل اثر تقلبات أسعار النفط على نمو الناتج المحلي الإجمالي الحقيقي في دولة الكويت وذللك للتوصل إلى الجوانب السلبية والايجابية في حال ارتفاع أو انخفاض أسعار النفط ومعرفة الآليات الواجب إتبات التباعها. إضافة إلى ذلك فان اغلب الدراسات التي تتاولت تقلبات أسعار النفط اقتصرت على العوامل الاقتصادية الكلية الأسمية بشكل عام ولم تتتاول نمو الناتج المحلي الإجمالي الحقيقي لوحده. كما قد تفيد الدراسة الحالية العاملين في القطاع النفطي، ووزارة الصناعة وغير ها من الوزارات، وخاصة عند إعداد ميز انية دولة الكويت. منهجية الدراسة:

من أجل تحقيق أهداف الدراسة تم الاعتماد على المنهج الاستتباطي و التحليلي، وكذلك الاسلوب الوصفي لما يمتاز به من قدرة على توفير البيانات والحقائق عن المشكلة وتفسير ها والوقوف على دلالتها كما ويمكن من جمع أدلة تجريبية من عدد كبير من البيانات الخاصة بتقلبات أسعار النفط، فضلاً عن استخدام الاسلوب الكمي وتحليل البيانات. مصادر جمع البيانات: تعتمد الدر اسة على المصادر الثانوية في جمع البيانات من خلال النشر ات والمو اقع الالكترونية و الدر اسات السابقة والكتب و الدوريات

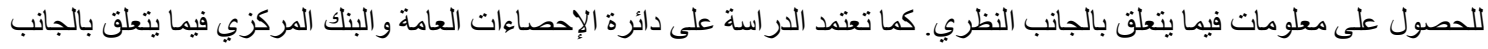
العملي للار اسة.

البند الثاني :الاسواق والاسعار النفطية_ الاطار المفاهيمي المطلب الاول : الاسواق النفطية واسعار النفط: أولاً :مفهوم السوق : يمكن تعريف السوق بشكل عام بأنه التقاء العرض و الطلب للسلع و الخدمات او رؤوس الأمو ال في قطاع محدد

ومعين، كما يمكن ان يعرف بانه عبارة عن علامات مكتشفة من طرف المستهلك تعبر عن نوع المنتوج (Demure , 1999: 29). ولقد عرفه Kotler بانه " مجموعة من الزبائن قادرين ور اغبين في القيام بتبادل يسمح لهم بإنشباع حاجة او رغبة ويمكن ان تستعمل كلمة السوق حسب مفهومين مختلفين ومتكاملين ايضاً حيث ينظر لها بمفهوم ضيق ويعني مجموع المعطيات الرقمية عن أهمية هيكلة وتطور

مبيعات منتوج ما) (Martin and Vedrine, 1996: 21).

مفهوم الأسواق النفية: هو المكان الطبيعي او الوهي مكانياً او جغر افياً لحدوث عملية تبادل للسلعة النفطية خاصة الخام منها بين الأطر اف المتبادلة، وكذلك يعرف بانه السوق التي يتم فيها التعامل بصدر مهم من مصادر الطاقة وهو النفطويحرك هذا السوق قانون العرض و الطلب مع بعض التحفظات بالإضافة الى العوامل الاقتصادية التي تحكم السوق هناك عو امل أخرى كالعو امل السياسية والعسكرية وتضارب المصالح المشتركة والمنتجين و الثركات النفطية. (الصباح، 2007: 15). وتتميز السوق النفطية بثلاث خصائص وهي : 


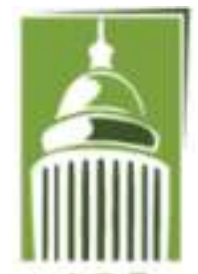

ARF

\section{Global Proceedings Repository \\ American Research Foundation}

ISSN 2476-017X

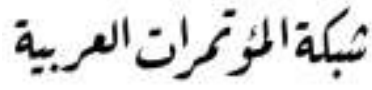

http://arab.kmshare.net/

Available online at http://proceedings.sriweb.org

_ـسوق احتكار القلة: يحتكر السوق النفطية عدد قليل من الثركات " منافسة القلة " و هو نوع من الاحتكار الجزئي وتعمل هذه القلة من الثركات و البلدان على التركيز على عدد قليل من المشروعات الضخمة تؤثر بشكل مباشر على العرض الكلي للنفط الخام. ـالاتجاه نحو التكامل الر اسي: ان المنتجين القلة يتحكمون في انتاج النفط ونقله وتكريره وتسويقه فان هذه العمليات بربطها نوع من التكامل

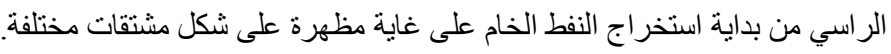
_الاتجاه نحو التكتل: ان حركة الثركات في السوق النفطية تدل على الاتفاقات المسبقة فيما بينها على الخطو ات التي تتبعها كل منها حتى التى

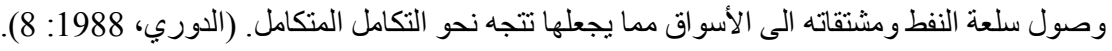
ثانياً :مفهوم أسعار النفط الخام :

Hيُعرفتُ السعر بشكل عام: (( هو نسبة المبادلة بين سلعتين )) و السعر عادة يقوم بالوحدة النقدية مثلا الدينار أو الدولار ( ( Hirshlifer and .et at , 2005: 29

وقد عرفهُ الاقتصادي (هاربر) بأنه: كمية النقود التي يدفعها المشتري إلى البائع لقاء سلعة أو خدمة فالسعر هنا هو القيمة النقدية للسلعة أو

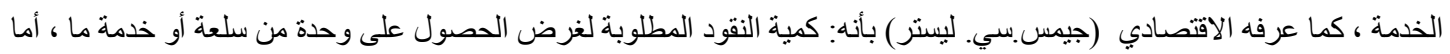
الاقتصادي (كارل ماركس) فقد عرف السعر بأنه: الاسم النقدي لقيمة السلعة (السامر ائي، 1987: 10).

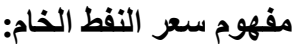

ويعرف سعر النفط الخام أيضاً بأنه: القيمة النقية أو الصورة النقدية لبرميل النفط الخام بالمقياس الأمريكي للبرميل المكون من (42) غالون معبراً عنه بالدولار الأمريكي عبر فترات تطور الصناعة النفطية (الهيتي، 1994: 152). المطلب الثاني : النمو الاقتصادي اولاً_ مفهوم النمو الاقتصادي : نظر اللأهمية الكبيرة التي تميز بها النمو الاقتصادي في التحليل الاقتصادي فقد تعددت وتتوعت تعاريفه و هذا ناتج من اختلاف اراء الدفكرين و المحللين و اختلاف أماكنهم وبيئاتهم وعلى هذا الأساس يمكن ان نسرد مجموعة من هذه التعاريف:

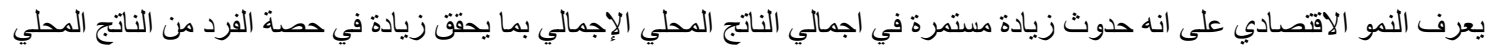

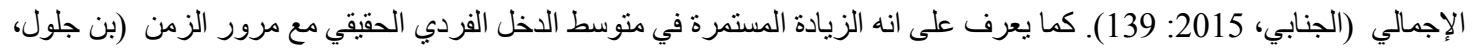

(60: 2009 ثنانياً_عناصر النمو الاقتصادي : يوجد العديد من العناصر التي تحدد النمو الاقتصادي والتي توضع في شكل مجتمعات تتمثل أساسا في العمل وراس المال إضافة التقدم التكنولوجي ويتم تركييها في مستويات ونسب عقلانية تضمن تحقيق مستوى معين للإنتاج وهي (ريان، 2015: 9 - 10): 1-العمل: هو عبارة عن مجموع القدر ات الفيزيائية والفكرية التي يمكن للإنسان استخدامها في انتاج السلع و الخدمات الضرورية لتلبية

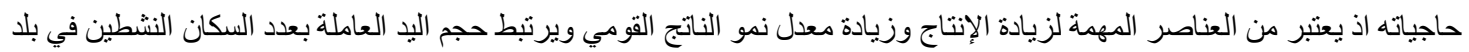
وساعات العمل التي يبذلها العامل إضافة الى زيادة عدد السكان. 2-راس المال: يعرف راس المال على انه مجموع السلع و الخدمات التي توجد في لحظة معينه في اقتصاد معين، كما يمثل راس المال

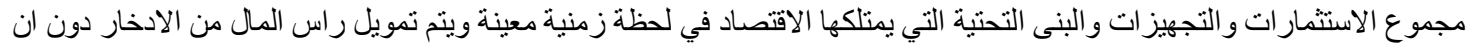




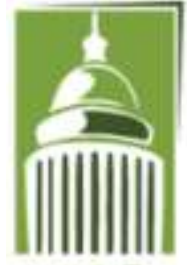

ARF
Global Proceedings Repository

American Research Foundation

ISSN 2476-017X

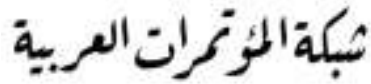

http://arab.kmshare.net/

Available online at http://proceedings.sriweb.org

تكون هناك فجوة بين الاثثين، حيث ان زيادة الادخار تؤدي الى زيادة الاستثمار ومن غير الممكن تطور بقاء الأمو ال المدخرة بدون

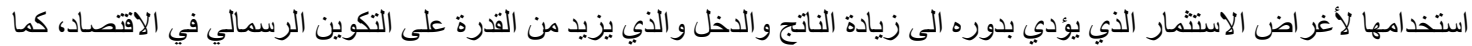
يمكن ان يكون راس المال عن طريق البنية التحتية للاقتصاد التي تساعد في تسريع العملية الإنتاجية وفي استثمار ات البنية التحتية للاقتصاد

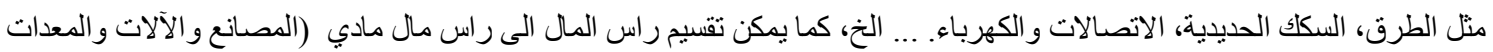
وغيرها) وراس مال بشري متمثل باستثمار العنصر البشري في التعليج و التنديب والصحة. 3-التقدم التكنولوجي: هو تنظيم جديد للإنتاج بسمح بالاستخدام الأكثر فاعلية للمو ارد المتاحة والتي توظف بطريقة اكثر كفاءة أي (انتاج

كمية اكبر من المنتوج بنفس كميات عناصر الإنتاج المتاحة او انتاج نفس الكمية من المنتوج بكميات اقل من عناصر الإنتاج) او بطريقة

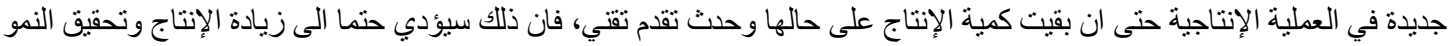
الاقتصادي وبالر غم من صعوبة قياس الناتج العلمي للعلماء بشكل دقيق الا ان الانفاق الكلي على البحث و التطوير يمثل مؤشر أ واسع القبول.

\section{المطلب الثالث : تحليل واقع النمو الاقتصادي في الكويت

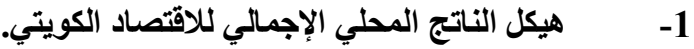

يعتمد الاقتصاد الكويتي بدرجة كبيرة على قطاع النفط اذ تنكل نسبة مساهمته في تكوين الناتج المحلي الإجمالي نسب مرتفعة جداً مقارنةً مع الإع القطاعات الأخرى اذ تجاوزت نسبته 60\% من الناتج المحلي الإجمالي في الكثير من السنوات خلال المدة 1990-2015 في حين لم تتخفض نسبته في تكوين الناتج المحلي الإجمالي في اسوء الظروف 36\% من مقارنة بالقطاعات الأخرى التي كانت نسبتها منخفضة وكما موضح

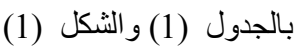

جدول (1) نسبة مساهمة النفط في تكوين الناتج المحلي الاجمالي بالمقارنة مع بعض القطاعات في الكويت للمدة(19922015) نسبة مئوية

\begin{tabular}{|c|c|c|c|c|c|c|c|}
\hline والخدمات الاجتماعية المجتمع & والنقل والتخزين & والبناء & والغاز والمياه & التحويلية & النفط & الزراعة وصيد & السنوات|القطاعات \\
\hline 23.7 & 4.4 & 2.9 & 1.3 & 8.6 & 40.1 & 0.3 & 1993 \\
\hline 23.9 & 4.8 & 3.2 & 1.4 & 10.4 & 37.6 & 0.4 & 1994 \\
\hline 23.0 & 4.5 & 3.0 & 1.9 & 11.0 & 38.7 & 0.4 & 1995 \\
\hline 20.6 & 4.1 & 2.6 & 1.3 & 11.7 & 43.8 & 0.4 & 1996 \\
\hline 22.1 & 4.3 & 2.6 & 1.6 & 13.2 & 39.5 & 0.4 & 1997 \\
\hline 27.5 & 5.5 & 2.9 & 2.9 & 11.7 & 29.8 & 0.4 & 1998 \\
\hline
\end{tabular}




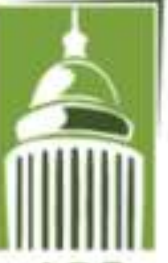

ARF

\section{Global Proceedings Repository}

American Research Foundation

ISSN 2476-017X

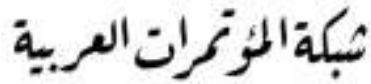

http://arab.kmshare.net/

Available online at http://proceedings.sriweb.org

\begin{tabular}{|l|l|l|l|l|l|l|l|}
\hline 24.5 & 5.3 & 2.6 & 2.6 & 11.1 & 36.3 & 0.4 & 1999 \\
\hline 20.8 & 4.5 & 2.2 & 2.2 & 7.1 & 48.8 & 0.4 & 2000 \\
\hline 23.1 & 5.3 & 2.4 & 2.4 & 6.4 & 43.7 & 0.5 & 2001 \\
\hline 21.9 & 5.1 & 2.7 & 2.4 & 7.8 & 38.2 & 0.5 & 2002 \\
\hline 19.2 & 5.6 & 2.4 & 2.1 & 7.9 & 40.8 & 0.5 & 2003 \\
\hline 16.8 & 6.0 & 2.3 & 1.8 & 8.3 & 44.8 & 0.4 & 2004 \\
\hline 13.7 & 5.2 & 1.9 & 1.4 & 7.3 & 52.0 & 0.3 & 2005 \\
\hline 12.1 & 6.6 & 1.8 & 1.1 & 5.5 & 56.0 & 0.2 & 2006 \\
\hline 12.6 & 7.3 & 1.8 & 1.0 & 5.5 & 52.5 & 0.2 & 2007 \\
\hline 12.0 & 6.5 & 1.5 & 0.9 & 4.4 & 59.1 & 0.2 & 2008 \\
\hline 16.7 & 9.0 & 1.9 & 1.4 & 5.1 & 49.4 & 0.3 & 2009 \\
\hline 16.2 & 7.0 & 2.1 & 1.5 & 5.6 & 53.8 & 0.2 & 2010 \\
\hline 15.4 & 5.4 & 1.8 & 1.8 & 5.6 & 63.5 & 0.4 & 2011 \\
\hline 15.5 & 5.0 & 1.7 & 1.8 & 6.0 & 65.4 & 0.4 & 2012 \\
\hline 16.3 & 5.0 & 1.8 & 1.9 & 5.9 & 63.5 & 0.4 & 2013 \\
\hline 18.9 & 5.1 & 2.1 & 2.1 & 5.9 & 60.5 & 0.4 & 2014 \\
\hline 19.1 & 5.5 & 2.7 & 2.5 & 6.1 & 60.7 & 0.4 & 2015 \\
\hline
\end{tabular}

الدصدر : المجموعة الاحصائية السنوية اعداد مختلفة (1993-2015) 
شكل (1) نسبة مساهمة النفط الخام في تكوين الناتج المحلي الإجمالي في الكويت للمدة 1993-2014 (نسبة مؤية)

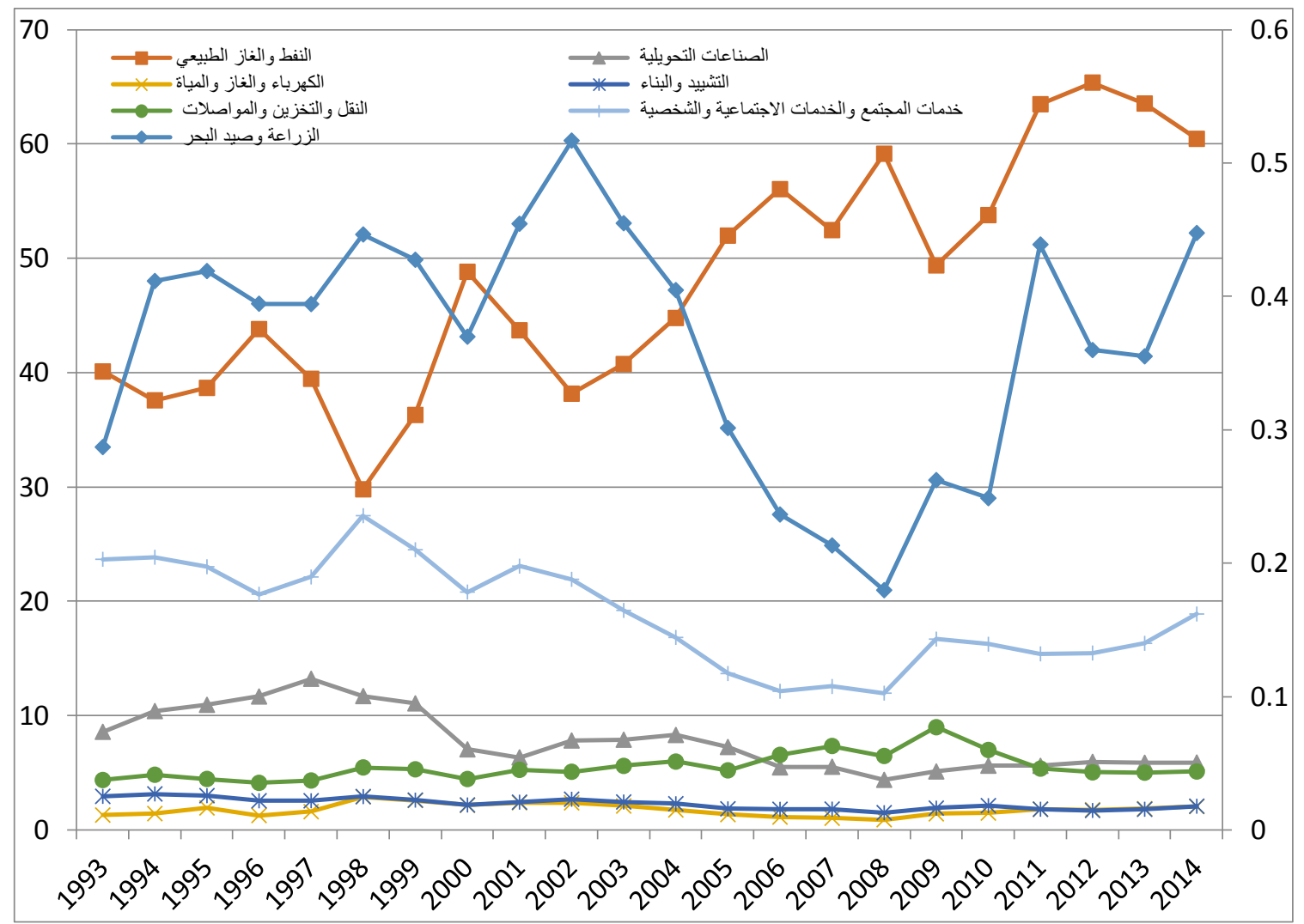

المصدر: من عمل الباحثان بالاعتماد على المجموعة الإحصائية اعداد مختلفة 1993-2015

سبقت الإثشارة الى الناتج المحلي الإجمالي و الذي يتحدد أساسا بأداء القطاع النفطي ونتيجة للأوضاع الجيدة في السوق للنفط الخام خلال السنو ات القليلة الماضية، اذ تذبذب معدل نمو الناتج المحلي الإجمالي الجاري والذي قد ينعكس في كثير من الأحيان الى التذبذبات الحاصلة في أسعار النفط الخام خلال المدة 1990-2015 وكما موضح بالجدول (2) فقد تراجعت معدلاته في عام 1997 و 1998 وقد يعود السبب

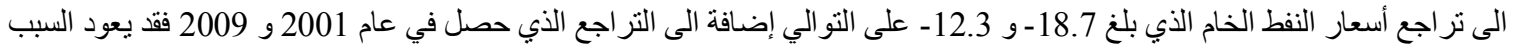

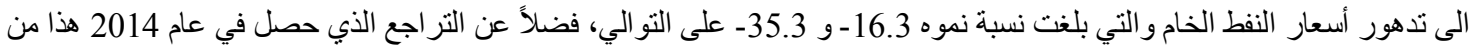
جانب، وكذللك الانخفاضات التي تحصل في الناتج المحلي الإجمالي الحققي لنفس الأعو ام من جهة أخرى. 


\section{Global Proceedings Repository \\ American Research Foundation}

ISSN 2476-017X

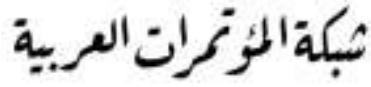

http://arab.kmshare.net/

Available online at http://proceedings.sriweb.org

جدول رقم (2) معدل نمو الناتج المحلي الاجمالي ومعدل نصيب الفرد في الكويت واسعار النفط الخام للمدة (1993 _ 2015)

\begin{tabular}{|c|c|c|c|}
\hline سعر النفط & بالأسعار الثابتة المحلي الاجمالي & بالأستعار الجارية المحلي الاجمالي & السنوات \\
\hline-11.4 & 34.0 & 24.1 & 1993 \\
\hline-4.9 & 8.4 & 2.1 & 1994 \\
\hline 9.0 & 4.9 & 9.9 & 1995 \\
\hline 20.1 & 0.6 & 16.2 & 1996 \\
\hline-7.9 & 2.5 & -2.4 & 1997 \\
\hline-34.2 & 3.7 & -14.1 & 1998 \\
\hline 42.3 & -1.8 & 16.0 & 1999 \\
\hline 57.7 & 4.7 & 26.2 & 2000 \\
\hline-16.3 & 0.7 & -7.5 & 2001 \\
\hline 5.2 & 3.0 & 8.3 & 2002 \\
\hline 16.0 & 17.3 & 23.1 & 2003 \\
\hline 27.7 & 10.8 & 22.8 & 2004 \\
\hline 40.6 & 10.1 & 34.7 & 2005 \\
\hline 20.8 & 7.5 & 24.9 & 2006 \\
\hline 13.1 & 6.0 & 10.6 & 2007 \\
\hline 36.8 & 2.5 & 21.6 & 2008 \\
\hline
\end{tabular}




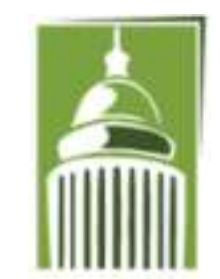

ARF
Global Proceedings Repository

American Research Foundation

ISSN 2476-017X

Available online at http://proceedings.sriweb.org

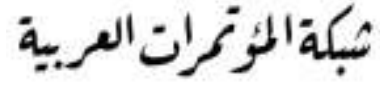

http://arab.kmshare.net/

\begin{tabular}{|r|r|r|r|}
\hline-35.3 & -7.1 & -23.1 & 2009 \\
\hline 26.8 & -2.4 & 8.5 & 2010 \\
\hline 38.7 & 9.6 & 28.5 & 2011 \\
\hline 1.9 & 6.6 & 14.6 & 2012 \\
\hline-3.2 & 1.1 & 1.4 & 2013 \\
\hline-48.2 & -1.6 & -5.7 & 2014 \\
\hline & 7.6 & 1.9 & 2015 \\
\hline
\end{tabular}

http://data.albankaldawli.org/country/kuwait

المطلب الرابع: تحليل العلاقة بين أسعار النفطومؤشرات النمو الاقتصادي في دولة الكويت

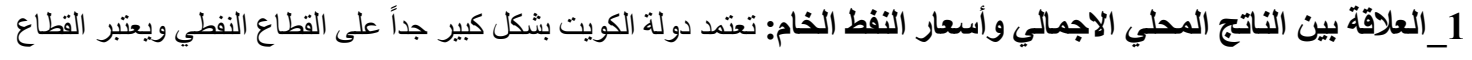
الأبرز من بين القطاعات الأخرى من خلال نسبة مساهته في تكوين الناتج المحلي الإجمالي، وبما ان سلعة النفط تعتبر سلعة عالمية يتحدد

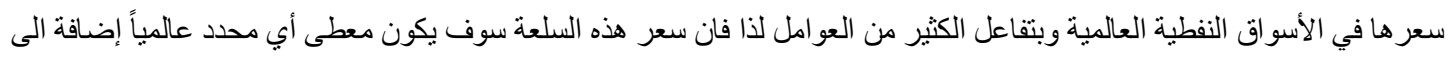

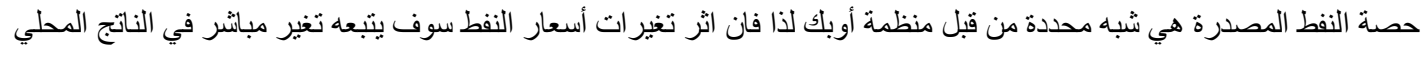
الإجمالي الجاري و الحقيقي وان الأخير ما هو الا عبارة عن مجموع السلع في أسعار ها، وخصوصاً وان دولة الكويت التي يثكل النفط الخام

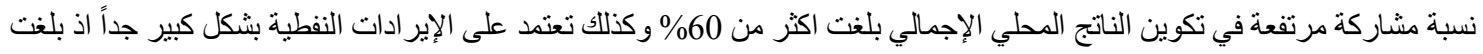
نسبة مشاركة العو ائد النفطية في تكوين الناتج المحلي الإجمالي الحقيقي اكثر من 65 \% 


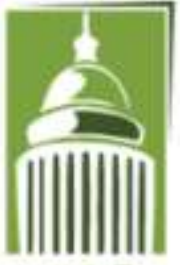

ARF
Global Proceedings Repository

American Research Foundation

ISSN 2476-017X

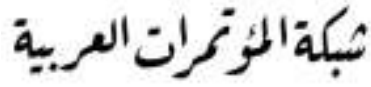

http://arab.kmshare.net/

Available online at http://proceedings.sriweb.org

شكل (2) الناتج المحلي الإجمالي الجاري في دولة الكويت مع أسعار النفط الخام للمدة 1992-2015

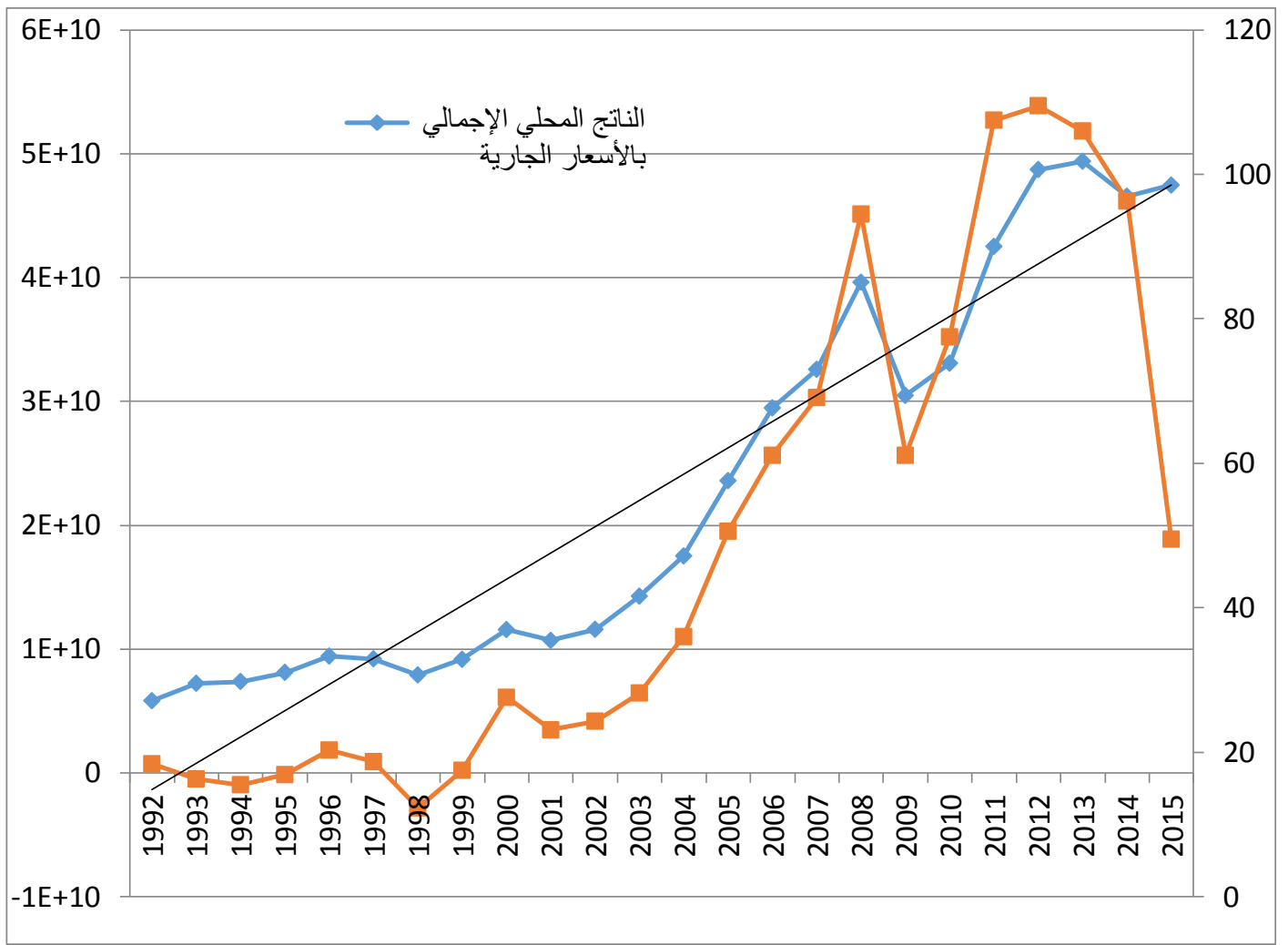

المصدر: من عمل الباحثان بالاعتماد على بيانات الملحق 1

ويمكن الاستعانة بالأشكال البيانية (2) و (3) و التي تبين مدى علاقة الناتج المحلي الإجمالي الجاري و الحقيقي بأسعار النفط الخام، وان هذان التاني

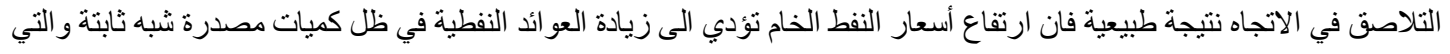

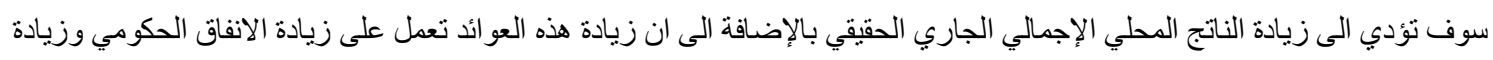

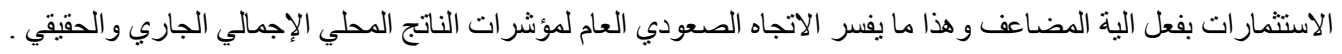




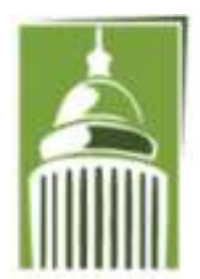

ARF

\section{Global Proceedings Repository}

American Research Foundation

ISSN 2476-017X

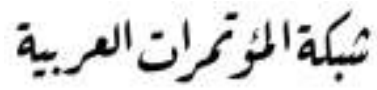

http://arab.kmshare.net/

Available online at http://proceedings.sriweb.org

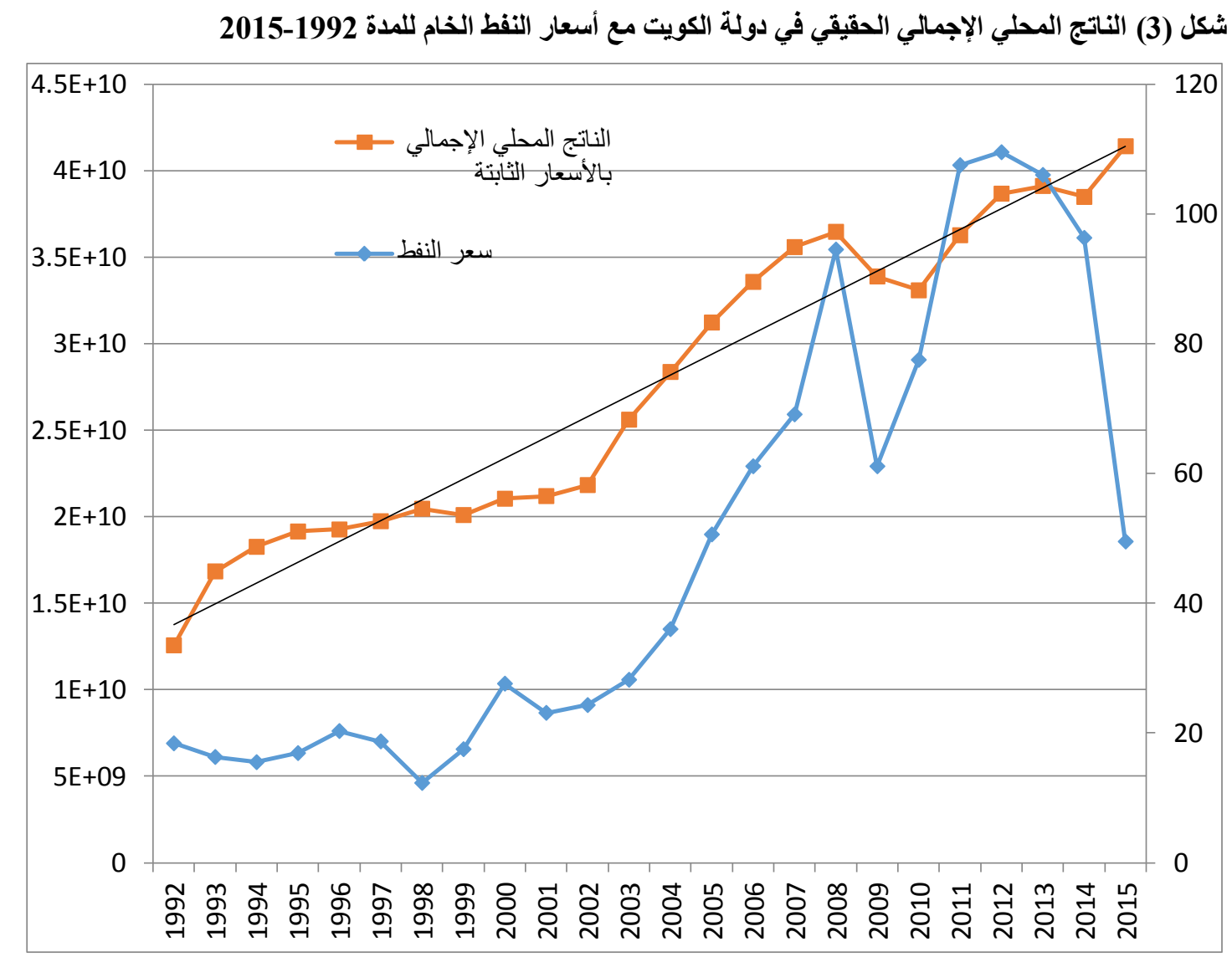

المصدر: من عمل الباحثان بالاعتماد على بيانات الملحق (1)

ثالثاً : توصيف النموذج القياسي وتحديد المتغيرات

1_الأساليب القياسية والبيانات المستخدمة: لتحليل الأثر بين التغيرات في أسعار النفط على مؤشرات النمو الاقتصادي، تم توظيف

الأدوات القياسية التالية: 


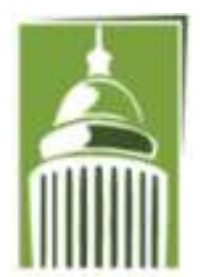

ARF

\section{Global Proceedings Repository \\ American Research Foundation}

ISSN 2476-017X

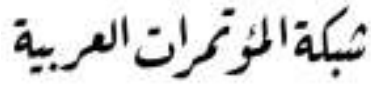

http://arab.kmshare.net/

Available online at http://proceedings.sriweb.org

Stationary أ-|ختبارات الاستقرارية

يعد شرط الاستقرار أساسيا في دراسة وتحليل السلاسل الزمنية، وإذا لم نكن السلاسل الزمنية مسنتقرة فانه لن يتم الحصول على نتائج سليمة ومنطقية، لذا سنقوم بنطبيق الاختبارات التالية للكثف عن استقرارية السلاسل الزمنية: • اختبار ديكي- فولر المعل Dickey and Fuller (خugmented Dickey-Fuller ADF) في عام 1981 طُور ديكي فولر البسيط لتحليل طبيعة وخصائص السلاسل الزمنية اطلق عليه اختبار ديكي فولر الموسع (ADF) وذللك لتفادي سلبيات اختبار ديكي فولر البسيط، والمتمثلة في عدم الاخذ بنظر الاعتبار مشكلة الارتباط الذاتي في حد الخطأ العشوائي، ويقوم ADF بتقدير معادلة الانحدار للصيغة التي قدمتها دراسة (Dickey and Fuller,1981):

$\Delta Y_{t}=a_{0}+a_{1} y_{t-1}+a_{2} t+\sum_{j=1}^{p} \gamma_{j+1} \Delta Y_{t-j}+\varepsilon_{t}$

$$
\text { حيث ان }
$$

SY معالجة مشكلة الارتباط الذاتي في التقلير بإضافة الفروق الاولى المبطأة للمتغير التابع $\Delta Y_{t-j}$ كمتغيرات مفسرة لأنها تؤدي إلى تحويل سلسلة البواقي إلى سلاسل مستقرة من النوع White Noise بدون ان تؤثر على توزيع الاحصاءات. وطبقا للمعادلة (4) فان الفرض الصفري H0 وهو وجود جذر الوحدة (عدم الاستقرار) مقابل استقرار الاتجاه في السلسلة الزمنية الواحدة. ويمكن كتابة الفرض الصفري

$$
\begin{aligned}
& \text { والفرض البديل على النحو التالي: } \\
& \text { H0:a1=0 } \\
& \text { H0:a1<0= } \\
& a_{1}=\rho-I \quad \text { حيث ان }
\end{aligned}
$$

اما t الاحصائية والتي يطلق عليها ناو ( tau ( فيتم تعديلها وفق الصيغة التالية: 


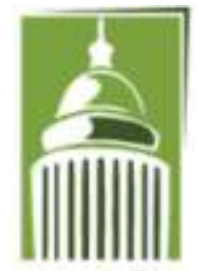

ARF
Global Proceedings Repository

American Research Foundation

ISSN 2476-017X

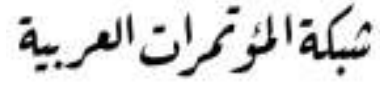

http://arab.kmshare.net/

Available online at http://proceedings.sriweb.org

$t_{a}=a /(\operatorname{se}(a))$

\author{
حيث ان a المعلمة المقدرة، (a) se الخطأ المعياري للمعلمة المقدرة. \\ يتم استخدام اختبار ديكي فولر الموسع للمقارنة بين قيم(t) المقدرة مع القيتها المجدولة.
}

Phillip-Perron (PP) •

يختبر فيلبس بيرون (Phillip and Perron, 1988:335) الفرض الصفري وهو وجود جذر الوحدة مقابل سكون الاتجاه

ايضا، لكن من خلال توظيف اختبار لا معلمي (Verbeek , 2004:273 لصيغة ديكي -هفولر غير المعلة (التي لا يضاف اليها الفروق الاولى المبطأة للمتغير التابع كمتغيرات تفسيرية) وبذلك يعالج مشكلة الارتباط الذاتي بثكل بديل وتستخدم الصيغة الاتية في تقدير اختبار PP (Kozhan,2009:73)

$\Delta Y_{t}=a_{0}+a_{1} y_{t-1}+a_{2} t+e_{t}$

حيث يمثل et حالة الاستقرارية، ان افضلية اختبار PP على اختبار ADF في انه بأخذ بنظر الاعتبار امكانية وجود اخطاء

مترتبة على ثبات الثناين في الثقدير المستخدم، ومن ثم يتم تصحيح الاخطاء المعيارية للمعلمات المقدرة ويعكس الطبيعة الديناميكية في السلسلة، ويكون نقدير التباين كالتالي (عطية، 2000: 631):

$S_{u}^{2}=T^{-1} \sum_{i=1}^{T} \hat{U_{t}^{2}}+2 T^{-1} \sum_{j=1}^{L} \sum_{t=j+1}^{T} \hat{U} \hat{U}$

حيث تمثل T حجم العينة ويمنل L معامل إنهاء التباطؤ.

يعد اختبار Robust لعدم توافر شروط نوزيع حد الخطأ العشوائي النقليدية، كما انه لا يسمح لأخطاء عشوائية ومتتوعة ذات تباين متغير ومرتبط ذاتياً، وان لاختبار (P-P test) نفس توزيع ديكي فولر، اذ يتم استخدام القيم الحرجة نفسها للاختبارين، وكما ان لاختبار فلييس بيرون نفس الصيغ التي يأخذها اختبار ديكي فولر ، الاولى بدون حد ثابت وبدون اتجاه عام 


\section{Global Proceedings Repository \\ American Research Foundation}

ISSN 2476-017X

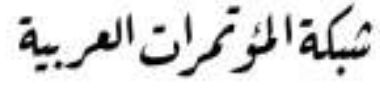

http://arab.kmshare.net/

Available online at http://proceedings.sriweb.org

None والثانية تأخذ الحد الثابت فقط Constant لافتراض ان متوسط السلسلة لا بساوي صفر، اما الصيغة الثالثة فتأخذ الحد الثابت مع الاتجاه العام Constant and Linear Trend ليعكس اتجاه السلسلة نحو الزيادة.

Engle and Granger, ) أ-ختبار انجل - كرانجر للتكامل المشترك: تعتمد منهجية انجل وجراتجر على خطوتين وهما

الخطوة الأولى: بعد النحقق من استقرار السلاسل الزمنية للمتغيرات فاذا كانت النتائج تدل على استقرار السلاسل الزمنية للمتغيرات في مستوياتها الاصلية فهذا يعني ان المتغيرات متكاملة تكاملا مثتركا ومن ثم بمكن استخدام الطرق الاحصائية النقليدية للتقدير، اما اذا كانت السلاسل الزمنية غير مستقرة في مستوياتها الاصلية وتصبح مستقرة بعد اخذ الفرق الاول لها او الثاني وتكون منكاملة من نفس الدرجة، فيتم تقدير نموذج العلاقة النوازنية الطويلة الاجل وفق الصيغة الآتية:-

$$
Y_{t}=\beta_{0}+\beta_{1} X_{t}+e_{t}
$$

$$
\text { وباستخدام طريقة المربعات الصغرى، فيتم بعد ذلك اختبار استقرار البواقي (e }
$$

فnit Root فإذا تم قبول فرضية العدم ( 0 ف أي ان سلسلة البواقي غير مستقرة يعني ذلك عدم وجود تكامل مشترك بين متغيرات السلاسل الزمنية في النموذج، والعكس في حالة التوصل الى رفض فرضية العدم ( 1 > 1 : H0 )، بسنتتج من ذلك بان سلسلة البوافي المقدرة لا تحتوي على جذر وحدة أي إنها مسنقرة ويستتنج من ذلك وجود تكامل مشترك بين متغيرات السلاسل الزمنية (وجود علاقة طويلة الأجل بين هذه المتغيرات). Error ) الخطوة الثانية: ان التوصل الى نتائج تثنير الى وجود علاقة طويلة الاجل بين المتغيرات فلابد من تقدير نموذج تصحيح الخطأ المorrection Model)، لغرض معرفة العلاقة في الأجل القصير ، أو التذبذب قصير الأجل حول اتجاه العلاقة في الأجل الطويل، ويتم William and ) تقدير هذا النموذج بإدخال البواقي المقدرة في الانحدار طويل الاجل كمتغير مستقل مبطأ لفترة واحدة ووفقاً للمعادلة النالية : (Greene, 2003:654

$$
\Delta Y_{t}=a_{1} \Delta X_{t}+a_{2} e_{t-1}+e_{t}
$$




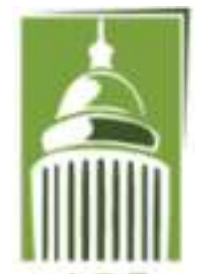

ARF

\section{Global Proceedings Repository \\ American Research Foundation}

ISSN 2476-017X

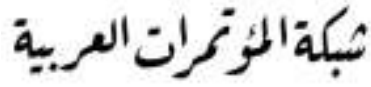

http://arab.kmshare.net/

Available online at http://proceedings.sriweb.org

اذ يشير الرمز د الى الفرق الاول، (e) الى حد الخطأ، وهنا يجب ان يكون معامل حد الخطأ المقدر سالب الاثشارة ومعنوي

احصائياً، حيث يمثل هذا المعامل نسبة اختلال التوازن في المتغير التابع التي يمكن تصحيحها من فترة الى اخرى، ويسمى بنموذج تصحيح الخطأ (Error Correction Model)، فهو بأخذ في نظر الاعتبار التفاعل الحركي في الاجل القصير والطويل بين التتغيرات ومحدداتها، حيث يمنل معامل حد تصحيح الخطأ (t) نسبة اختلال التوازن في الفترة السابقة (t) (t) التي يتم تحصيلها او تعديلها في الفترة

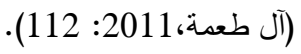

1 -البيانات المستخدمة وشكل العلاقة: سيتم استخدام أربعة متغيرات تابعة تمثل النمو الاقتصادي وهي (الناتج المحلي الإجمالي الجاري Y، الناتج المحلي الإجمالي الحقيقي Y1، معدل دخل الفرد الجاري ا، معدل دخل الفرد الحقيقي I1) ومتغير واحد تفسيري منمتل بسعر النفط O وتم الاعتماد على بيانات منظمة البلدان المصدرة للنفط (أوبك) وكذلك على بيانات البنك الدولي للإنثاء والتعمير وفيما يلي توضيح للمتغيرات:

الناتج المحلي الإجمالي الجاري = الناتج المحلي الإجمالي بالأسعار الجارية للعملة المحلية

الناتج المحلي الإجمالي الحقيقي = الناتج المحلي الإجمالي بالأسعار الثابتة للعملة المحلية سعر النفط =سعر سلة أوبك

ولتحديد آثر تغيرات أسعار النفط على مؤشرات النمو الاقتصادي ينبين من خلال العلاقة التي تربط بين هذه المتغيرات وفقاً للمنطق الاقتصادي وكما يلي:

$$
\begin{aligned}
& \text { يوجد اثر طردي لارتفاع أسعار النفط الخام O على الناتج المحلي الإجمالي الجاري } \\
& \text { يوجد اثر طردي لارتفاع أسعار النفط الخام O على الناتج المحلي الإجمالي الحقيقي } \\
& \text { رابعا: عرض النتائج وتحليلها }
\end{aligned}
$$

1- نتائج الاستقرارية: يتبين ومن خلا النتائج التي نم التوصل اليها في جداول (3) و (4) ان جميع المتغيرات غير مسنقرة في مستوياتها وانها تصبح مسنقرة بعد اخذ الفرق الأول هذا ما بينته نتائج اختبار دوكي فولر ADF وفيليس بيرون PP اذ جاءت قيمة t المحتسبة اقل من قيمتها الجدولية في المستوى الأصلي للييانات في كلا الاختبارين ولجميع المتغيرات عند مستوى معنوية 


\section{Global Proceedings Repository \\ American Research Foundation}

ISSN 2476-017X

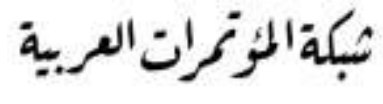

http://arab.kmshare.net/

ARF

Available online at http://proceedings. sriweb.org

1\% وهذا ما يدل على عدم استقرار السلاسل الزمنية للمتغيرات في مستوياتها الاصلية، اما عند اخذ الفرق الأول للبيانات فأن

قيمة t المحتسبة تصبح اكبر من قيمتها الجدولية وفي كلا الاختبارين ولجميع المتغيرات عند مستوى معنوية 1\% وهذا يعني ان

السلاسل الزمنية للمتغيرات مستقرة عند الفرق الأول.

ADF الجدول (3) نتائج الاستقرارية حسب اختبار دوكي فولر

\begin{tabular}{|c|c|c|}
\hline \multirow[b]{2}{*}{ الحد الثابت مع الاتجاه } & المستويات & \multirow[b]{2}{*}{ لمتغيرات } \\
\hline & الحد الثابت & \\
\hline-1.99223 & 0.197557 & $\mathrm{Y}$ \\
\hline-3.13086 & -0.16306 & Y1 \\
\hline-2.13803 & -0.74875 & I \\
\hline-2.93823 & -3.19163 & $\mathrm{I} 1$ \\
\hline-2.54976 & -0.42309 & $\mathrm{O}$ \\
\hline-3.77 & -2.67429 & $1 \%$ \\
\hline
\end{tabular}

"تعني الفرق الثاني

E Views المصدر: من عمل الباحثان بالاعتماد على مخرجات 


\section{Global Proceedings Repository \\ American Research Foundation}

ISSN 2476-017X

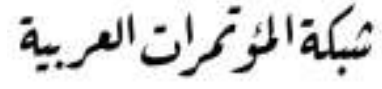

http://arab.kmshare.net/

Available online at http://proceedings.sriweb.org

الجدول (4) نتائج الاستقرارية حسب اختبار فيلييس بيرون PP

\begin{tabular}{|c|c|c|c|c|c|c|c|c|}
\hline \multicolumn{4}{|c|}{ الفروق } & \multicolumn{4}{|c|}{ المستويات } & \multirow{3}{*}{ المتغيرات } \\
\hline الاتجاه & الحد الذا & \multicolumn{2}{|c|}{ العد الثابت } & & & \multicolumn{2}{|c|}{ الحد الثابت } & \\
\hline P.Vol & $\mathrm{T}$ & P.Vol & $\mathrm{T}$ & P.Vol & $\mathrm{T}$ & P.Vol & $\mathrm{T}$ & \\
\hline 0.0376 & -3.79646 & 0.0098 & -3.79544 & 0.5965 & -1.9472 & 0.9767 & 0.370471 & $\mathrm{Y}$ \\
\hline 0 & -7.35769 & 0 & -6.68994 & 0.5515 & -2.03454 & 0.6958 & -1.10257 & Y1 \\
\hline 0.0356 & -3.82366 & 0.0074 & -3.9266 & 0.4678 & -2.19724 & 0.8006 & -0.7957 & I \\
\hline 0.0043 & -4.88465 & 0.0008 & -4.91781 & 0.6626 & -1.81518 & 0.3788 & -1.78217 & I1 \\
\hline 0 & -7.95934 & 0.0002 & -5.57394 & 0.3118 & -2.53052 & 0.9152 & -0.26726 & $\mathrm{O}$ \\
\hline & -4.4679 & & -3.78803 & & -4.44074 & & -3.7696 & $1 \%$ \\
\hline
\end{tabular}

E Views المصدر : من عمل الباحثان بالاعتماد على مخرجات

2-تقدير دوال النمو الاقتصادي: بعد التوصل الى استقرار السلاسل الزمنية لجميع المتغيرات عند اخذ الفرق الاول لها سيتم

تقدير كل من دالة الناتج المحلي الإجمالي الجاري ودالة الناتج المحلي الإجمالي الحقيقي Y1 ودالة معدل دخل الفرد الجاري ا ودالة معدل دخل الفرد الحقيقي 11 وكما يلي:

أ- - تقلير دالة الناتج المحلي الإجمالي الاسمي: أوضحت النتائج المبينة في الجدول (8) المعنوية الاحصائية لاثر أسعار النفط

الخام على الناتج المحلي الإجمالي الاسمي هذا ما أكدته قيمة t المحتسبة، وان أسعار النفط O تؤثر على كل من الناتج المحلي

الإجمالي الجاري Y، وأكدت قيمة F المحتسبة معنوية الدالة من الناحية الإحصائية وان التغير بأسعار النفط الخام بمقدار دولار

واحد سوف يؤدي الى ارتفاع الناتج المحلي الإجمالي الاسمي بمقدار 43600000 دينار كويتي. 


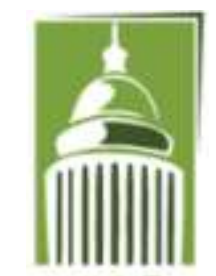

ARF

\section{Global Proceedings Repository \\ American Research Foundation}

ISSN 2476-017X

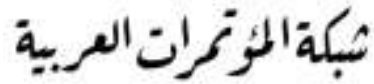

http://arab.kmshare.net/

Available online at http://proceedings.sriweb.org

الجدول (5) نتائج تقدير دالة الناتج المحلي الإجمالي الجاري

\begin{tabular}{|r|r|r|r|r|}
\hline Variable & Coefficient & Std. Error & t-Statistic & Prob. \\
\hline $\mathrm{C}$ & 1000000000.0 & 737000000.0 & 1.4 & 0.1896 \\
\hline $\mathrm{O}$ & 436000000.0 & 12494281.0 & 34.9 & 0 \\
\hline R-squared & 0.95 & Mean dependent var & 22000000000.0 \\
\hline Adjusted R-squared & 0.95 & S.D. dependent var & 15300000000.0 \\
\hline S.E. of regression & 2040000000.0 & Akaike info criterion & 45.8 \\
\hline Sum squared resid & 87600000000000000000.0 & \multicolumn{2}{|c|}{ Schwarz criterion } & 45.9 \\
\hline Log likelihood & -524.6 & \multicolumn{2}{|c|}{ Hannan-Quinn criter. } & 45.8 \\
\hline F-statistic & 1216.2 & \multicolumn{2}{|c|}{ Durbin-Watson stat } \\
\hline Prob (F-statistic)
\end{tabular}

المصدر: من عمل الباحثان بالاعتماد على مخرجات E Views

ب- تقدير دالة الناتج المحلي الإجمالي الحقيقي: بينت النتائج المبينة في الجدول (6) المعنوية الاحصائية لاثر أسعار النفط

الخام على الناتج المحلي الإجمالي الحققي، هذا ما أكدنه قيمة t المحتسبة، وان ارتفاع أسعار النفط الخام بمقدار دولار واحد

سوف يؤدي الى زيادة الناتج المحلي الإجمالي الحقيقي بمقار 227000000 دينار كويتي، وأكدت قيمة المحتسبة معنوية

$$
\text { الدالة من الناحية الإحصائية. }
$$

الجدول (6) نتائج تقدير دالة الناتج المحلي الإجمالي الحقيقي Y1

\begin{tabular}{|l|l|l|l|l||}
\hline Variable & Coefficient & Std. Error & t-Statistic & Prob. \\
\hline C & 16100000000.0 & 1070000000.0 & 14.9 & 0.0 \\
\hline O & 227000000.0 & 18196006.0 & 12.5 & 0.0 \\
\hline R-squared & 0.96 & Mean dependent var & 27000000000.0 \\
\hline Adjusted R-squared & 0.96 & S.D. dependent var & 8420000000.0 \\
\hline S.E. of regression & 2970000000.0 & Akaike info criterion & 46.5 \\
\hline
\end{tabular}




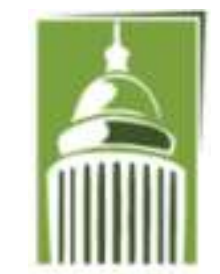

ARF

\section{Global Proceedings Repository \\ American Research Foundation}

ISSN 2476-017X

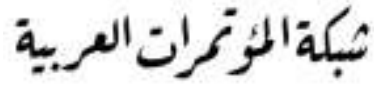

http://arab.kmshare.net/

Available online at http://proceedings.sriweb.org

\begin{tabular}{|l|l|l|l||}
\hline Sum squared resid & 186000000000000000000.0 & Schwarz criterion & 46.6 \\
\hline Log likelihood & -533.3 & Hannan-Quinn criter. & 46.6 \\
\hline F-statistic & 155.5 & Durbin-Watson stat & 0.7 \\
\hline Prob (F-statistic) & 0.0 & & \\
\hline
\end{tabular}

E Views المصدر: من عمل الباحثان بالاعتماد على مخرجات

هـ - نتائج العلاقة التوازنية الطويلة الاجل: بعد تقدير دوال النمو الاقتصادي في الكويت ينبغي معرفة وجود علاقة طويلة الاجل بين المتغيرات ام لا وهذا ما يتم توضيحه من خلال اختبار استقرارية البواقي لدوال النمو الاقتصادي والمتمنل بدالة الناتج المحلي الإجمالي الجاري Y ودالة الناتج المحلي الإجمالي الحقيقي Y1 ، فقد اكدت النتائج بان سلاسل البواقي المقدرة لجميع الدوال جاءت مستقرة بمستوياتها الاصلية والتي تعني ان هناك علاقة نوازنية طويلة الاجل وهذا ما تبينه الجداول (10و 11) والاثكال (4 و5 ). جاول (10) نتائج استقرارية البواقي لالة الناتج المحلي الإجمالي الجاري

\begin{tabular}{|c|c|c|}
\hline P-P & $\mathrm{ADF}$ & \\
\hline-3.82431 & -3.543691 & معامل التقاطع \\
\hline-3.7696 & -2.67429 & $1 \%$ \\
\hline-3.00486 & -1.957204 & $5 \%$ \\
\hline-2.64224 & -1.608175 & $10 \%$ \\
\hline-3.65398 & -3.741398 & التقاطع مع الاتجاه \\
\hline-4.44074 & -3.77 & $1 \%$ \\
\hline-3.6329 & -3.19 & $5 \%$ \\
\hline-3.25467 & -2.89 & $10 \%$ \\
\hline
\end{tabular}

E Views المصدر : من عمل الباحثان بالاعتماد على مخرجات 


\section{Global Proceedings Repository \\ American Research Foundation}

ISSN 2476-017X

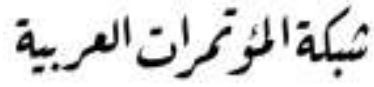

http://arab.kmshare.net/

Available online at http://proceedings.sriweb.org

الثكل (4) استقرارية البواقي لالة الناتج المحلي الإجمالي الجاري Y

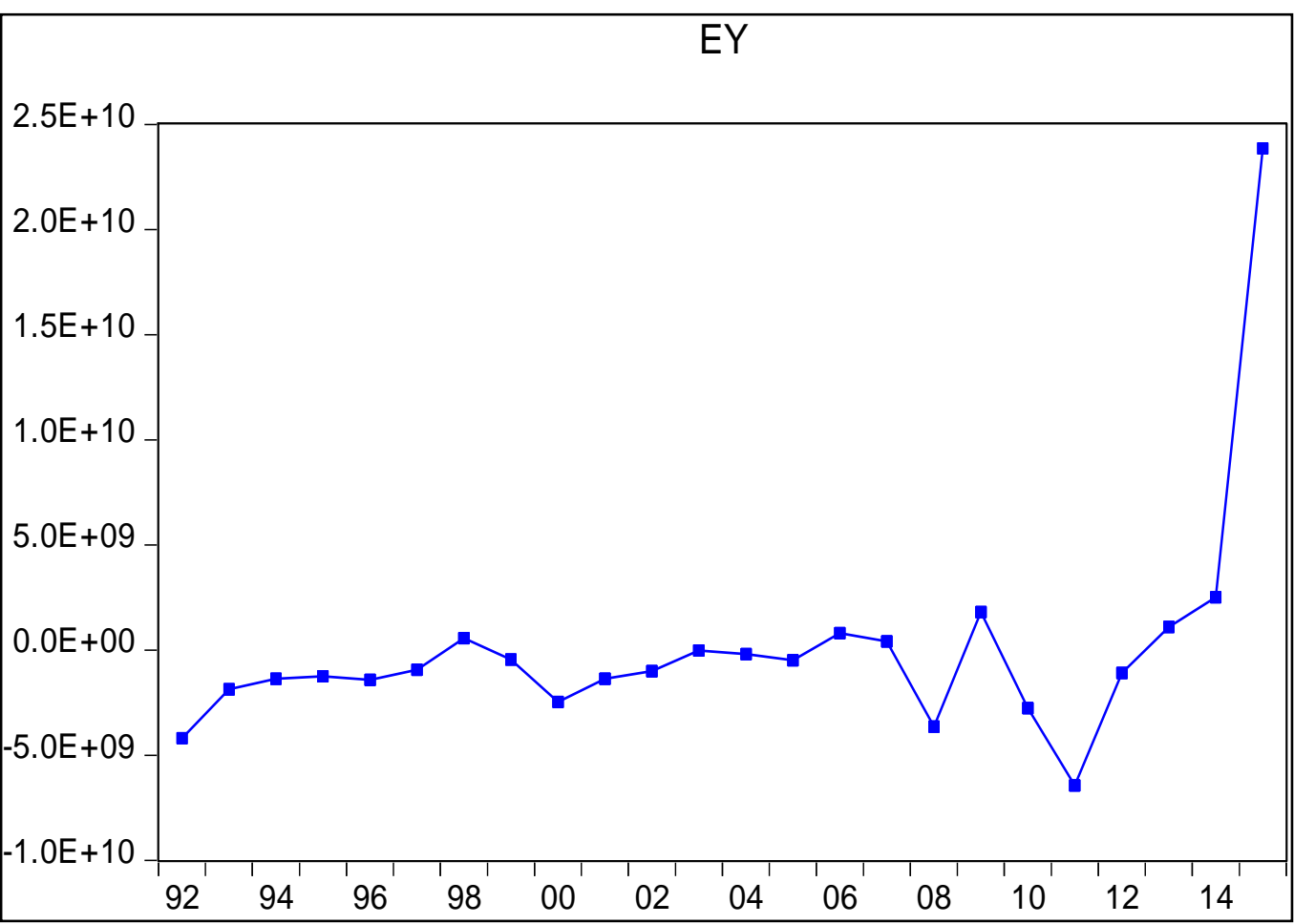

E Views المصدر : من عمل الباحثان بالاعتماد على مخرجات

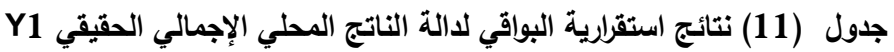

\begin{tabular}{|c|c|c|}
\hline P-P & ADF & \\
\hline-3.51901 & -2.328855 & معامل الثقاطع \\
\hline-3.7696 & -2.67429 & $1 \%$ \\
\hline-3.00486 & -1.957204 & $5 \%$ \\
\hline-2.64224 & -1.608175 & $10 \%$ \\
\hline-3.18207 & -2.826805 & التّاطع مع الاتجاه \\
\hline-4.44074 & -3.77 & $1 \%$ \\
\hline-3.6329 & $\begin{array}{l}-3.19 \\
\end{array}$ & $5 \%$ \\
\hline-3.25467 & -2.89 & $10 \%$ \\
\hline
\end{tabular}

E Views المصدر : من عمل الباحثان بالاعتماد على مخرجات 


\section{Global Proceedings Repository \\ American Research Foundation}

ISSN 2476-017X

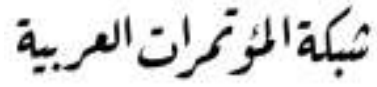

http://arab.kmshare.net/

Available online at http://proceedings.sriweb.org

الثكل (5) استقرارية البواقي لدالة الناتج المحلي الإجمالي الحقيقي

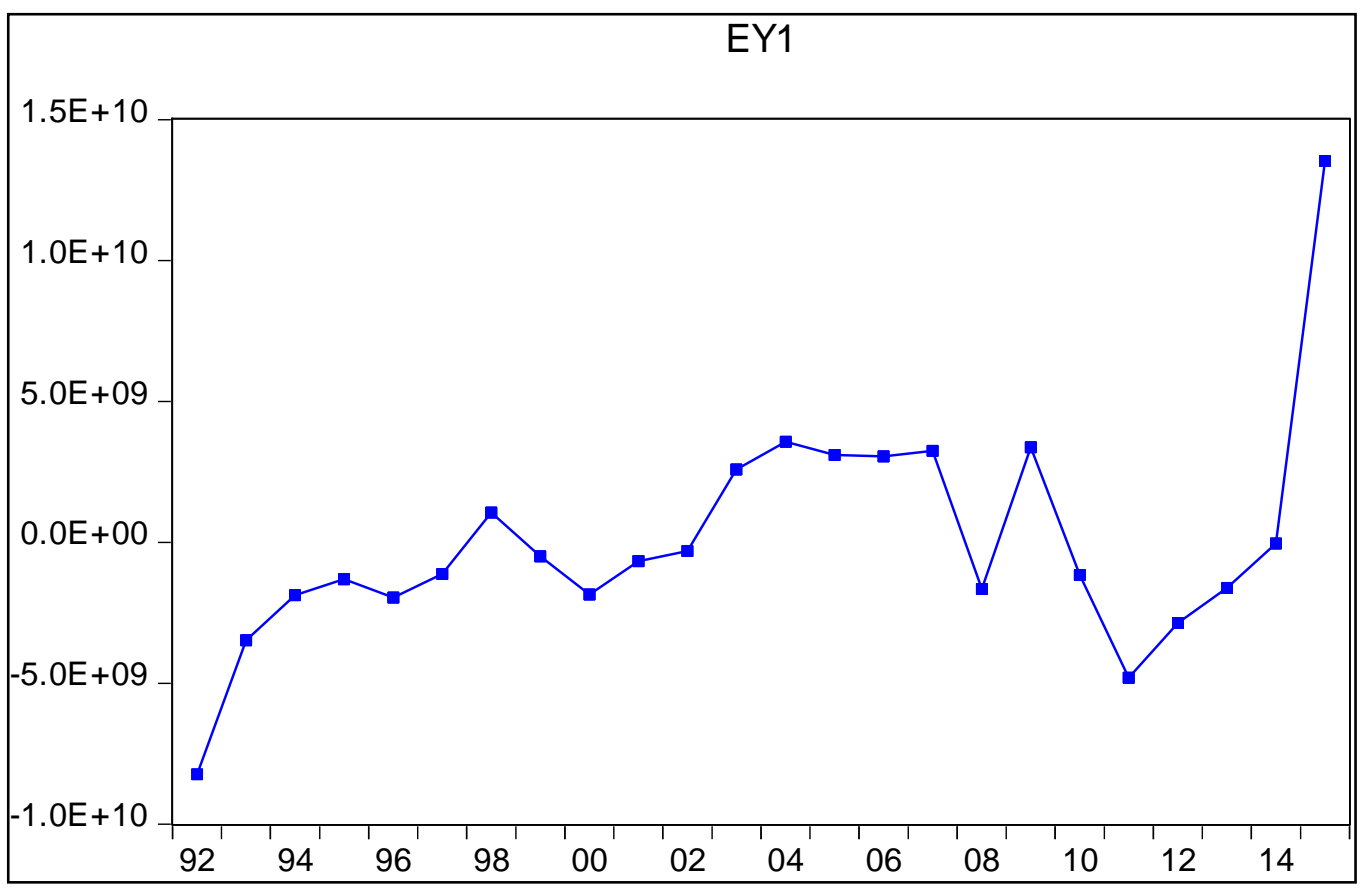

د- استقرارية دوال النمو الآقتصادي في الاجل الطويل: لغرض معرفة إمكانية التتبؤ لاثر أسعار النفط على مؤشرات النمو الاقتصادي

متمنلة بدالة الناتج المحلي الإجمالي الجاري Y ودالة الناتج المحلي الإجمالي الحقيقي Y1 ودالة معدل دخل الفرد الجاري ا ودالة معدل دخل الفرد الحقيقي 11 على التوالي، اذ يجب ان تكون الدوال مستقرة ويتين من خلال قراءة الاثكال ( 6 7) ان جميع الدوال تعاني من عدم الاستقرار وهذا يؤكد على عدم القدرة بالتتبؤ بمؤنشرات النمو الاقتصادي الامر الذي يضع أصحاب القرار امام مشكلة تحديد مؤشرات النمو الاقتصادي في الكويت بالاعتماد على أسعار النفط الخام. 


\section{Global Proceedings Repository \\ American Research Foundation}

ISSN 2476-017X

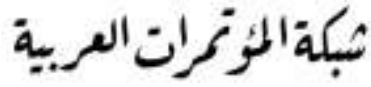

http://arab.kmshare.net/

Available online at http://proceedings.sriweb.org

الثكل (6) استقرارية دالة الناتج المحلي الإجمالي الجاري Y في الاجل الطويل

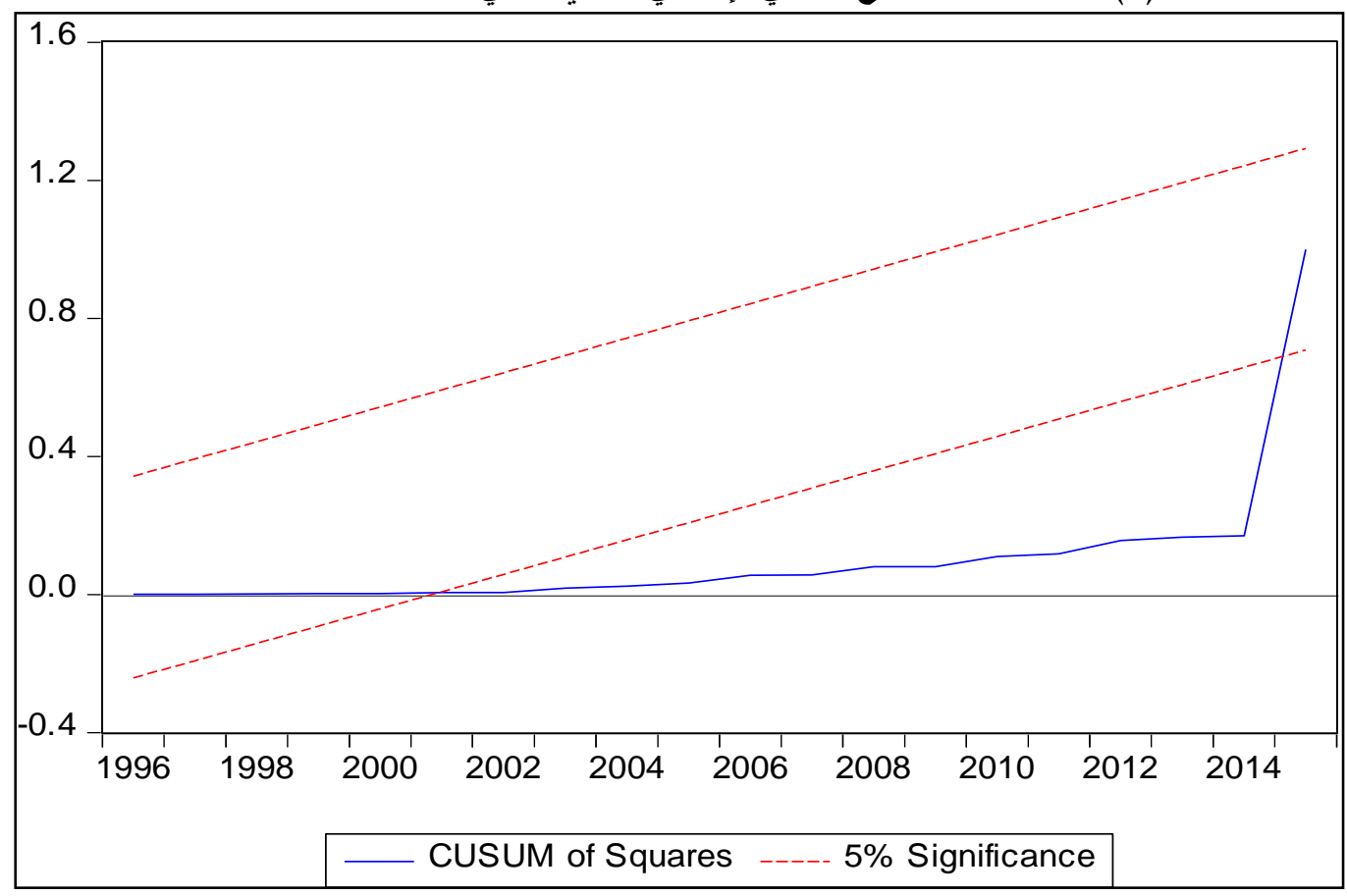

E Views المصدر : من عمل الباحثان بالاعتماد على مخرجات

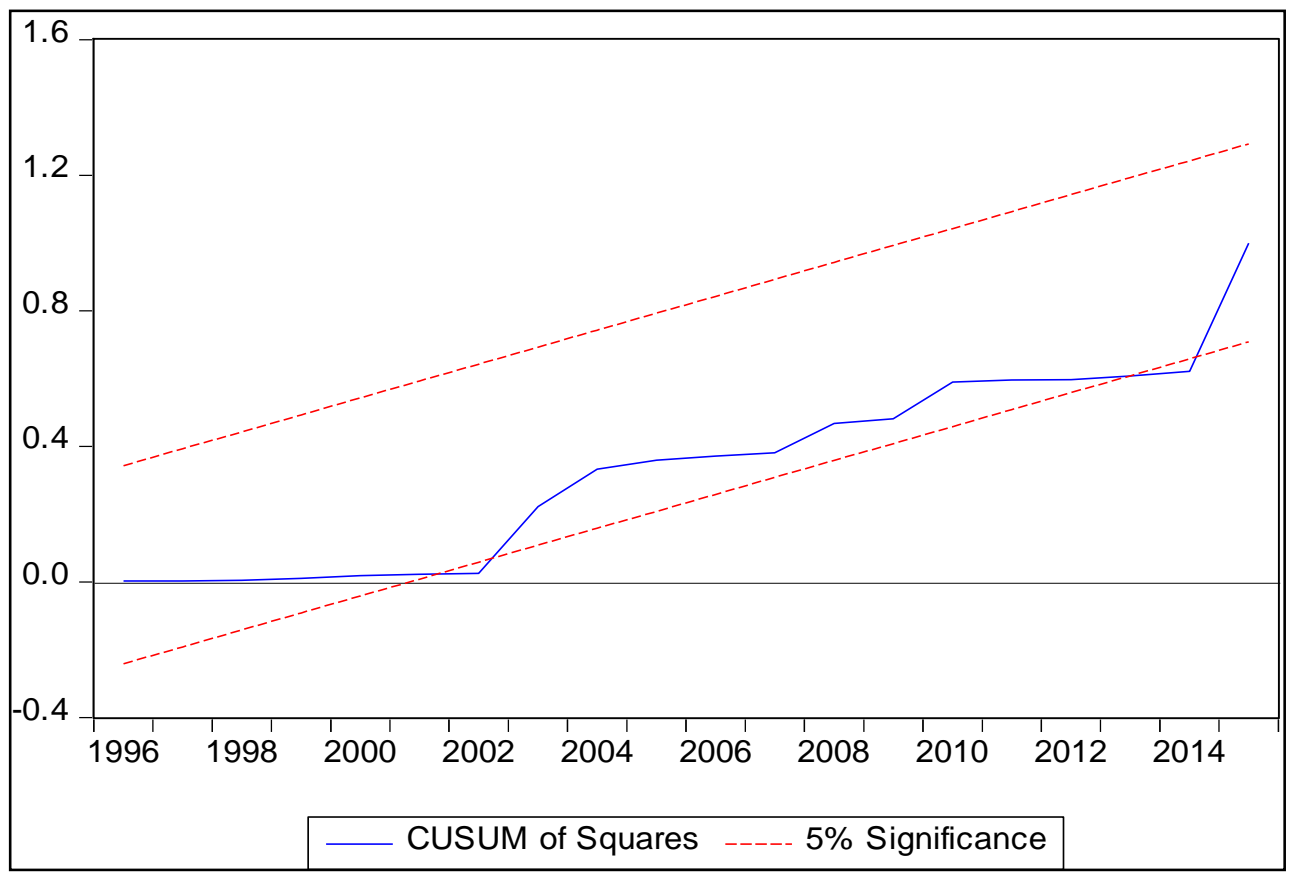




\section{Global Proceedings Repository \\ American Research Foundation}

ISSN 2476-017X

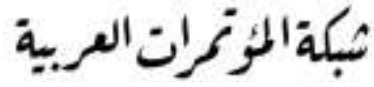

http://arab.kmshare.net/

Available online at http://proceedings.sriweb.org

\section{E Views المصدر : من عمل الباحثان بالاعتماد على مخرجات}

نتائج العلاقة التوازنية قصبرة الاجل: بعد التوصل الى علاقة نوازنية طويلة الاجل بين المتغيرات لذا لابد من اختبار العلاقة التوازنية قصبر الاجل ويتم ذلك من خلال ادخال متغير حد الخطأ المقدر والمتباطئ زمنياً في نموذج الاجل الطويل واخذ فروق المتغيرات وتقدير الدالة من جديد لمعرفة وجود علاقة قصيرة الاجل من عدمه وذلك من خلا إثارة معامل حد الخطأ ومعنويته الإحصائية، وهذا ما تم اختباره لدوال النمو الاقتصادي والمنتل بدالة الناتج المحلي الإجمالي الجاري Y ودالة الناتج المحلي الإجمالي الحقيقي Y1 على التوالي والنتائج مبينه في الجداول (12 و 13) والتي اكدت على وجود علاقة توازنية قصير الاجل. ويظهر الجدول (12) ان تصحيح اختلد الناتج المحلي الإجمالي الجاري يحتاج 6.6\% من السنة حتى يعود الى التوازن وما يعادل 7.2 اثهر تقريبا، في حين اظهرت نتائج التحليل المبينة في الجدول (13) ان تصحيح الاختلل الناتج المحلي الإجمالي الحقيقي يحتاج 0.2\% من السنة للعودة الى التوازن وهو ما يعادل 2.4 شهرا احصائياً

جدول (12) نتائج اختبار العلاقة قصيرة الاجل لدالة الناتج المحلي الإجمالي الجاري

\begin{tabular}{|r|r|r|r|r|}
\hline Variable & Coefficient & Std. Error & t-Statistic & Prob. \\
\hline $\mathrm{C}$ & 672000000.0 & 255000000.0 & 2.6 & 0.0 \\
\hline $\mathrm{D}(\mathrm{O})$ & 307000000.0 & 20453833.0 & 15.0 & 0.0 \\
\hline EY (-1) & -0.6 & 0.1 & -4.1 & 0.0 \\
\hline R-squared & 0.9 & Mean dependent var & 1850000000.0 \\
\hline Adjusted R-squared & 0.9 & S.D. dependent var & 3870000000.0 \\
\hline S.E. of regression & 1130000000.0 & Akaike info criterion & 44.7 \\
\hline Sum squared resid & 24400000000000000000.0 & Schwarz criterion & 44.8 \\
\hline Log likelihood & -488.3 & Hannan-Quinn criter. & 44.7 \\
\hline F-statistic & 112.9 & Durbin-Watson stat & 0.9 \\
\hline Prob (F-statistic) & 0.0 & & & \\
\hline
\end{tabular}

E Views المصدر : من عمل الباحثان بالاعتماد على مخرجات 


\section{Global Proceedings Repository \\ American Research Foundation}

ISSN 2476-017X

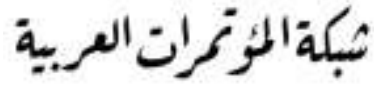

http://arab.kmshare.net/

Available online at http://proceedings.sriweb.org

جدال (13) نتائج اختبار العلاقة قصيرة الاجل لدالة الناتج المحلي الإجمالي الحقيقي

\begin{tabular}{|r|r|r|r|r|}
\hline Variable & Coefficient & Std. Error & t-Statistic & Prob. \\
\hline $\mathrm{C}$ & 847000000.0 & 300000000.0 & 2.8 & 0.0 \\
\hline $\mathrm{D}(\mathrm{O})$ & 91675945.0 & 25906257.0 & 3.5 & 0.0 \\
\hline EY1 (-1) & -0.2 & 0.1 & -2.2 & 0.0 \\
\hline R-squared & 0.4 & Mean dependent var & 1180000000.0 \\
\hline Adjusted R-squared & 0.3 & S.D. dependent var & 1650000000.0 \\
\hline S.E. of regression & 1340000000.0 & Akaike info criterion & 45.0 \\
\hline Sum squared resid & 33900000000000000000.0 & Schwarz criterion & 45.1 \\
\hline Log likelihood & -491.9 & Hannan-Quinn criter. & 45.0 \\
\hline F-statistic & 6.4 & Durbin-Watson stat & 0.9 \\
\hline Prob (F-statistic) & 0.0 & & & \\
\hline
\end{tabular}

E Views المصدر : من عمل الباحثان بالاعتماد على مخرجات

خلاصة الجانب النطبيقي: اكدت النتائج على وجود اثر طردي لأسعار النفط الخام على مؤشرات النمو الاقتصادي فقد جائ

النموذجان ليؤكدى لنا ذلك وهذا مما يثبت صحة الفرضية القائلة ان أرتفاع أسعار النفط تؤثر بشكل إيجابي على معدلات النمو الاقتصادي

في الاقتصاد الكويتي للمدة 1990-2015، كما بينت النتائج ان هناك علاقة نوازنية طويلة الاجل بين أسعار النفط الخام ومعدلات النمو

الاقتصادي اذ بينت نتائج استقرارية الخطأ للنموذجان انها مسنقرة في المستوى حسب اختبار دوكي فولر وكذلك النماذج الأول والثاني حسب

اختبار فلييس بارون إضافة الى ذلك فق أوضحت النتائج اختبار استثرارية دوال النمو الاقتصادي في الاجل الطويل لجميع النماذج (دالة

الناتج المحلي الإجمالي الجاري، دالة الناتج المحلي الإجمالي الحقيقي) انها غير مستقره وهذا يعني من غير المكن التتبؤ بمؤشرات النمو

الاقتصادي بالاعتماد على أسعار النفط الخام، وان الاختلال الذي يحصل في الناتج المحلي الإجمالي الجاري يصحح خلال 7.2 شهراً

نقريباً اما الاختلال الذي يحصل في الناتج المحلي الإجمالي الحقيقي فيصحح خلا 2.4 شهراً. 


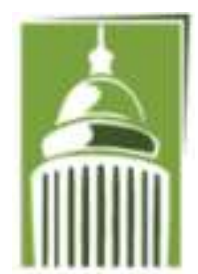

ARF

\section{Global Proceedings Repository \\ American Research Foundation}

ISSN 2476-017X

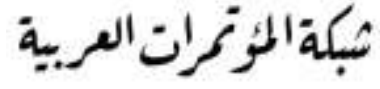

http://arab.kmshare.net/

Available online at http://proceedings.sriweb.org

المبحث الثالث: الاستتتاجات وإلتوصيات

1- 1 الاستنتاجات:

أ- - توجد علاقة طردية بين مؤشرات النمو الاقتصادي في دولة الكويت وأسعار النفط الخام وهذا ما اوضحته الاثكال البيانية للسلاسل الزمنية لكل متغيرات النمو الاقتصادي وأسعار النفط الخام.

ب- أثرت أسعار النفط الخام على مؤشرات النمو الاقتصادي في دولة الكويت خلال الددة 1992-2015 حيت ان تغير أسعار النفط الخام بمقدار دولار واحد يؤدي الى تغير بالناتج المحلي الإجمالي الجاري بمقدار 436000000 دينار كويتي وبشكل طردي وان تغير أسعار النفط الخام بمقدار دولار واحد يؤدي الى تغير الناتج المحلي الإجمالي الحقيقي بمقار بمقدار 227000000 دينار كويتي بشكل طردي،.

ت- توجد علاقة توازنية طوية الاجل بين مؤشرات النمو الاقتصادي (الناتج المحلي الإجمالي الجاري، الناتج المحلي الإجمالي الحقيقي) من جهة وأسعار النفط الخام من جهة أخرى، اذ بينت نتائج الجانب النطبيقي ان قيم حد الخطأ مستقرة عند المستوى الأصلي لجميع الدوال مما يؤكد بوجود علاقة توازنية طويلة الاجل.

ث- لا يمكن استخدام دوال النمو الاقتصادي (الناتج المحلي الإجمالي الجاري، الناتج المحلي الإجمالي الحقيقي،) للمدة 19922015 للتتبؤ بالاعتماد على أسعار النفط الخام، حيث جاءت نتائج استقرارية دوال النمو لتؤكد لنا ان جميع هذه الدوال غير مستقره ولا يمكن ان تعتمد في عملية النتبؤ. ج- هناك علاقة توازنية قصبرة الاجل بين مؤشرات النمو الاقتصادي (الناتج المحلي الإجمالي الجاري، الناتج المحلي الإجمالي الحقيقي،) وأسعار النفط الخام مما يعني ان الاختلال الذي يحصل في الناتج المحلي الإجمالي الجاري يصحح خلال 7.2 شهراً تقريباً اما الاختلال الذي يحصل في الناتج المحلي الإجمالي الحقيقي فيصح خلال 2.4 شهراً. 


\section{Global Proceedings Repository \\ American Research Foundation}

ISSN 2476-017X

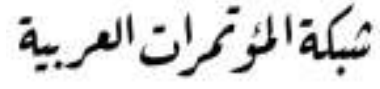

http://arab.kmshare.net/

Available online at http://proceedings.sriweb.org

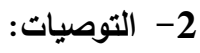

أ- - العمل على استثمار الفوائض النفطية النانجة عن الارتفاع الحاصل في أسعار النفط الخام وذلك من خلال القيام بمشاريع

استثمارية ستراتيجية.

ب- تتشيط القطاعات غير النفطية والعمل على زيادة نسبة مساهتها في تكوين الناتج المحلي الإجمالي لا سيما قطاع الصناعة

$$
\text { التحويلية وقطاع الزراعة وقطاع التامين والخدمات الأخرى. }
$$

ت- ت تقتين الإنتاج والتصدير لسلعة النفط من اجل حفظ حق الأجيال اللاحقة وعدم الاعتماد على العوائد النفطية في تمويل النفقات العامة اذ شكلت نسبة عالية في اغلب السنوات خلا الدة 1990-2015 وصلت الى أكثر من 92\% وهذا مؤشر سلبي حيث الانخفاض في أسعار النفط قد يؤدي الى عجز في الموازنة العامة لانها تعتمد على النفط بشكل خاص.

1- الدوري، محمد أحمد (1988)، أسباب ظاهرة تدهو أسعار البترول الخام في السوق الدولية، مجلة الإدارة والاقتصاد،

$$
\text { الجامعة المستتصرية، العدد 8، ك2، العراق. }
$$

2- آل طعمة، حيدر حسين احمد محمد (2011)، تحليل العلاقة بين عز الموانتة الحكومية وعجز الحساب الجاري (دراسة تطيقية لظاهزة العزز المزدوج في البلدان النامية)، أطروحة دكتوراه غير منشورة، كلية الإدارة والاقتصاد، جامعة بغداد،

العراق.

3- السامرائي، أسماء خضير ياس (1987)، العوامل الموئثة في أسعار النفط الخام في (أوبك)، رسالة ماجستير، غير منشورة،

$$
\text { جامعة بغداد، كلية الإدارة والاقتصاد . }
$$

4- بن جلول، خالد (2009)، (اثر ترقية الصادرات خارج المحروقات على النمو الاقتصادي دراسة تحيله قياسية لحالة الجزائر 1970_2006)، رسالة ماجستير في العلوم الاقتصادية ، غير منشورة ، كلية العلوم الاقتصادية وعلوم التسيير ، جامعة بن

$$
\text { يوسف بن خده ، الجزائر }
$$

5- عية، عبد القادر (2000)، (الاقتصاد القياسي بين النظرية والتطبيق)،الدار الجامعية للطباعة والنشر :الإسكندرية. 


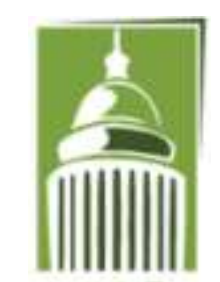

ARF

\section{Global Proceedings Repository \\ American Research Foundation}

ISSN 2476-017X

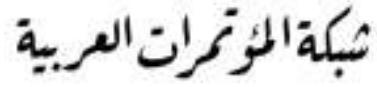

http://arab.kmshare.net/

Available online at http://proceedings.sriweb.org

6- ريان، زيد (2015)،(اثر ترقية الصادرات غير النفطية على النمو الاقتصادي دراسة حالة الجزائر للفترة

2005_2014)،رسالة ماجستير غير منشورة في العلوم التجارية ، كلية العلوم الاقتصادية والتجارية وعلوم التسيير، جامعة

محمد خيضر ،بسكرة:الجزائر.

7- الصباح، أحمد فهد الأحمد (2007)، النفط والغاز في الظليج العربي : نحو ضمان الأمن الاقتصادي، مركز الإمارات

للاراسات والبحوث الاستراتيجية : الطبعة الأولى، أبو ظبي.

8- الهيتي، أحمد حسين (1994)، مقدمة في اقتصاد النفط، دار الكتاب للطباعة والنشر : الموصل.

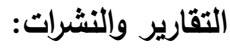

1- صندوق النقد العرب، التقرير الاقتصادي العبي الموحد، أبو ظبي، أبلول، من 1992الى 2000.

2- البنك الدولي (2015)، انخفاض أسعار النفط، منطقة الثرق الأوسط وشمال إفريقيا، الموجز الاقتصادي الفصلي لمنطقة

الثرق الأوسط وشمال إفريقيا ، العدد الرابع.

3- لجنة الكويت الوطنية للتنافسية (2006)، تقرير الكويت للنتافسية، مركز التميز في الإدارة، كلية العلوم الإدارية، جامعة الكويت،

الكويت من 2006 الى 2014.

المواقع الاكترونية:

1. (أوبك)، الموقع الرئيسي لمنظمة الأقطار المصدرة للبترول (أوبك)، على شبكة الأنترنيت:

http://www.opec.org

Kozhan, Roman, (2009) , (Financial Econometrics) - with Eviews ,bookbon

.http://bookboon.com/en/textbooks/finance/financial-econometrics-eviews

المراجع الاجنيبة:

1. Hirshlifer, j And, A. Glszer (2005), Price theory and Applications, CumbridgeVniversity press, Newyork ,.

2. Demeur, Clude(1999),(Marketing,paris:Dalloz). 


\section{Global Proceedings Repository \\ American Research Foundation}

ISSN 2476-017X

Available online at http://proceedings.sriweb.org

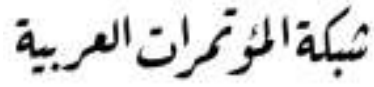

http://arab.kmshare.net/

A R F

3. Dickey, D. and Fuller, W. (1981), Likelihood Ratio Statistical for Autoregressive Time

Series with a Unit Root, Econometrica ., 1057-1072.

4. Engle R. F. and Granger, C. W, (1987), Co-integration and Error-Correction Representation, Estimation and Testing, Econometrics, vol.55, NO. 2, USA.

5. Johansen, S. (1988) Statistical Analysis of Cointegrating Vectors, Journal of Economic, Dynamics and Contro.

6. Martin,et.and p.vedrine,(1996),(Markiteng,Batne chihab).

7. Phillips, R., and P. Perron (1988), Testing for a Unit Root in Time Series Regression, Biometrika, Vol.57, P-P. 335

الملحق ـ (1) أسعار النفط الخام مؤشرات النمو الاقتصادي للمدة 1992 - 2015

(دينار - عملة محلية)

\begin{tabular}{|c|c|c|c|c|c|c|}
\hline & الناتج الجاري & الناتج الحقيقي & نصيب الفرد & نصيب الفرد & عدد السكان & النفط *أسعار \\
\hline 1992 & 5826500100 & 12565960600 & 6326.529 & 13644.37 & 920963 & 18.4 \\
\hline 1993 & 7230300200 & 16837189300 & 6999.857 & 16300.56 & 1032921 & 16.3 \\
\hline 1994 & 7379999700 & 18257602500 & 5391.604 & 13338.45 & 1368795 & 15.5 \\
\hline 1995 & 8114000000 & 19144610000 & 4956.534 & 11694.71 & 1637031 & 16.9 \\
\hline 1996 & 9429299900 & 19260459200 & 5756.924 & 11759.2 & 1637906 & 20.3 \\
\hline 1997 & 9206500000 & 19736833000 & 5459.729 & 11704.53 & 1686256 & 18.7 \\
\hline 1998 & 7907100100 & 20459606700 & 4476.78 & 11583.66 & 1766247 & 12.3 \\
\hline
\end{tabular}




\section{Global Proceedings Repository \\ American Research Foundation}

ISSN 2476-017X

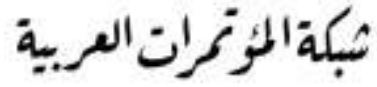

http://arab.kmshare.net/

Available online at http://proceedings.sriweb.org

\begin{tabular}{|c|c|c|c|c|c|c|}
\hline 1999 & 9169100100 & 20093582400 & 4947.84 & 10842.92 & 1853152 & 17.5 \\
\hline 2000 & 11570000000 & 21036892100 & 5996.465 & 10902.94 & 1929470 & 27.6 \\
\hline 2001 & 10701000000 & 21190256600 & 5377.327 & 10648.25 & 1990022 & 23.1 \\
\hline 2002 & 11590000000 & 21825964300 & 5675.21 & 10687.4 & 2042215 & 24.3 \\
\hline 2003 & 14267000000 & 25606221400 & 6806.798 & 12216.75 & 2095993 & 28.2 \\
\hline 2004 & 17517000000 & 28362012700 & 8085.973 & 13092.11 & 2166344 & 36 \\
\hline 2005 & 23593000000 & 31219755200 & 10422.76 & 13792.06 & 2263604 & 50.6 \\
\hline 2006 & 29470000000 & 33567558600 & 12333.13 & 14047.95 & 2389498 & 61.1 \\
\hline 2007 & 32581000000 & 35578813000 & 12834.28 & 14015.18 & 2538591 & 69.1 \\
\hline 2008 & 39620000000 & 36461112000 & 14645.38 & 13477.71 & 2705290 & 94.5 \\
\hline 2009 & 30478000000 & 33881086300 & 10578.07 & 11759.19 & 2881243 & 61.1 \\
\hline 2010 & 33079100000 & 33079100000 & 10812.03 & 10812.03 & 3059473 & 77.5 \\
\hline 2011 & 42511600000 & 36264100000 & 13124.18 & 11195.45 & 3239181 & 107.5 \\
\hline 2012 & 48722200000 & 38667100000 & 14248 & 11307.55 & 3419581 & 109.5 \\
\hline 2013 & 49392200000 & 39111400000 & 13744.15 & 10883.36 & 3593689 & 106 \\
\hline 2014 & 46564100000 & 38477000000 & 12406.77 & 10252 & 3753121 & 96.3 \\
\hline 2015 & $47464390116 *$ & $41406860422 *$ & $14203.88^{*}$ & $11226.14^{*}$ & & 49.5 \\
\hline
\end{tabular}

http://data.albankaldawli.org/country/kuwait 